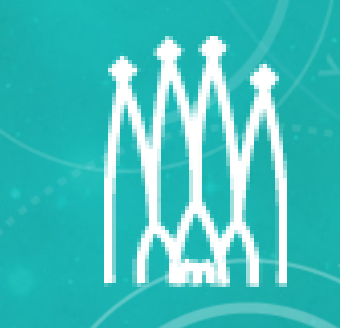

\title{
GRAPH-BASED DECISION MAKING FOR TASK SCHEDULING IN CONCURRENT GAUDI
}

1. SHAPOVAL ${ }^{1,2,3,4}$, M. CLEMENCIC ${ }^{1}$, B. HEG NER ${ }^{1}$, D. FUNKE ${ }^{1,5}$, D. PIPARO ${ }^{1}$, P. MATO ${ }^{1}$ CERN ${ }^{1}$, SWITZRLAND KIPT2, UKRAINE UNIFE', INFN-FE4, ITALY KTP, GERMANY

IEEE NSS/MIC 2015, San Diego, US 


\section{CONTENT}

- Introduction

- Concurrency control: reactive scheduling

- Speedup and scalability w ith reactive sc heduling

- Concurrency control: predictive scheduling

- Generic a nalysis of speed up constraints 


\section{GAUDI FRAMEWORK}

An object-oriented software architecture for event data processing applications in high energy physics domain.

* Designed on principles of:

$\checkmark$ Separation of algorithms and data

$\checkmark$ Composability and reusability

(via abstract interfaces)

* Written in $\mathrm{C}++$ and Python

* 150k SLOC 


\section{GAUDI FRAMEWORK}

An object-oriented software architecture for event data processing applications in high energy physics domain.

* Designed on principles of:

$\checkmark$ Separation of algorithms and data

$\checkmark$ Composability and reusability (via abstract interfaces)

* Written in $\mathrm{C}++$ and Python

* 150k SLOC
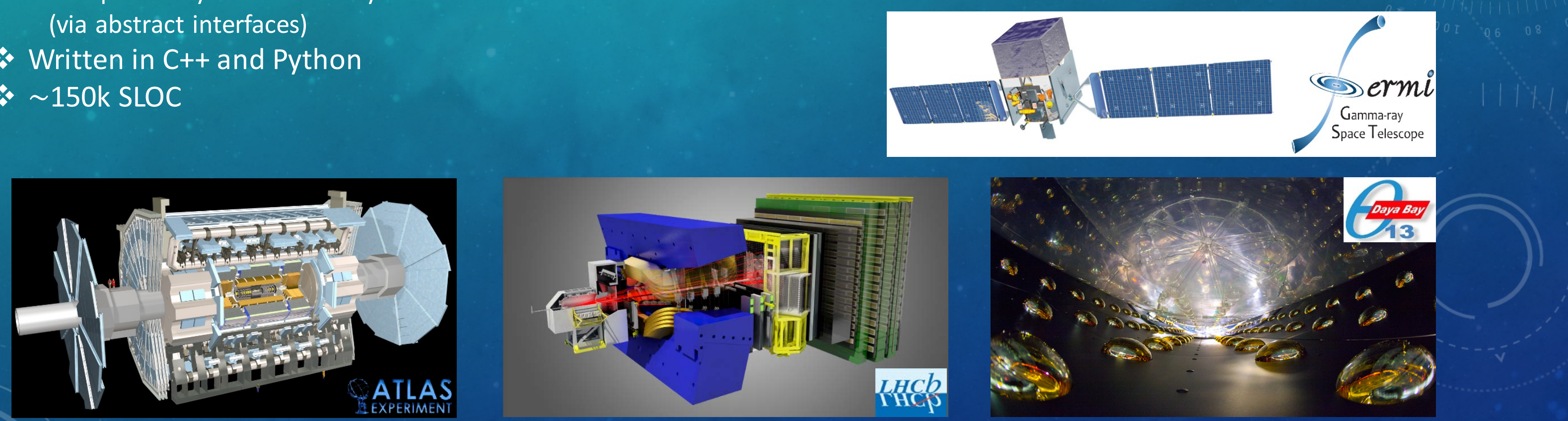


\section{GAUDI FRAMEWORK}

An object-oriented software architecture for event data processing applications in high energy physics domain.

* Designed on principles of:

$\checkmark$ Separation of algorithms and data

$\checkmark$ Composability and reusability (via abstract interfaces)

* Written in $\mathrm{C}++$ and Python

\& $\sim 150 \mathrm{k}$ SLOC

HL Triggering Reconstruction

Analyses

Detector simulation

Event display

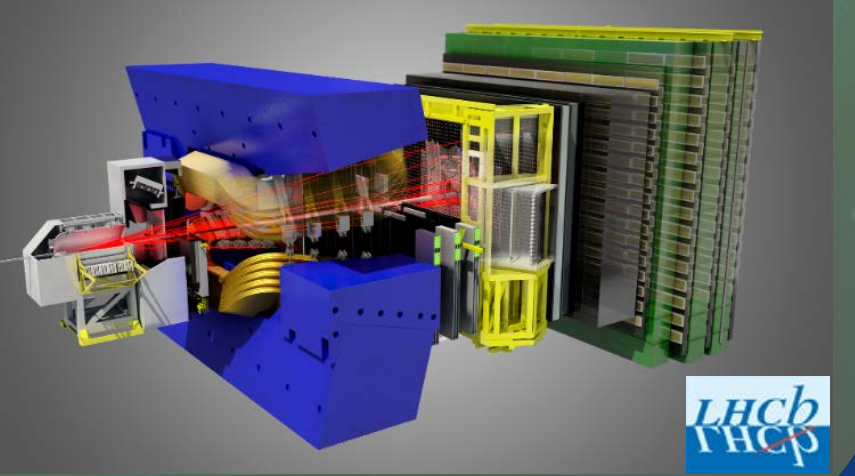

(C++ \& Python)
ATLAS and LHCb customization of Gaudi

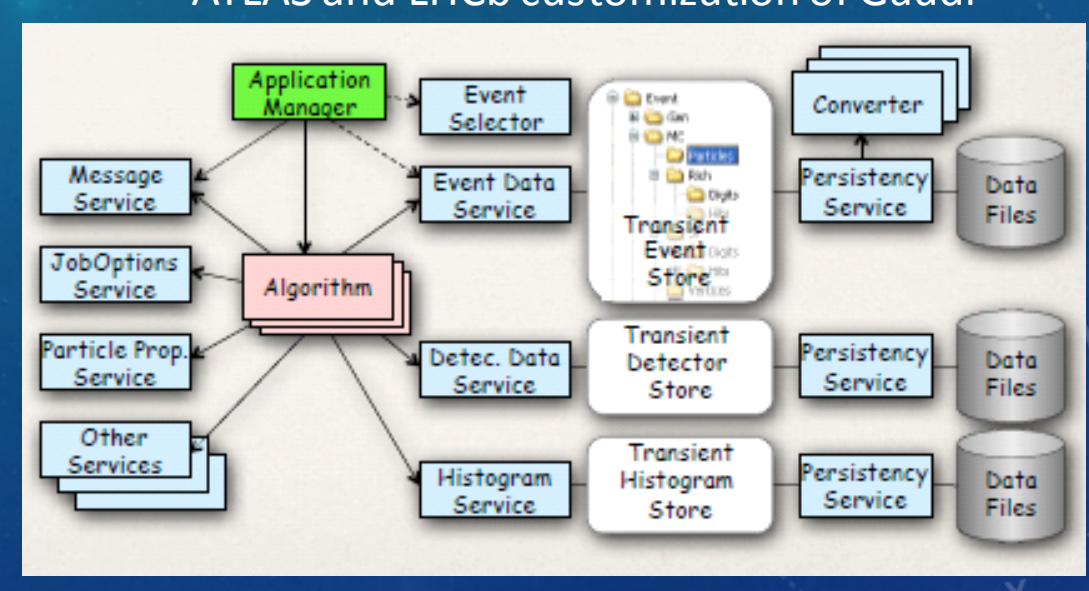




\section{CONCURRENT GAUDI (A.K.A. GAUDI HIVE)}

\section{A prototype of a multithreaded task-based incarnation of Gaudi.}
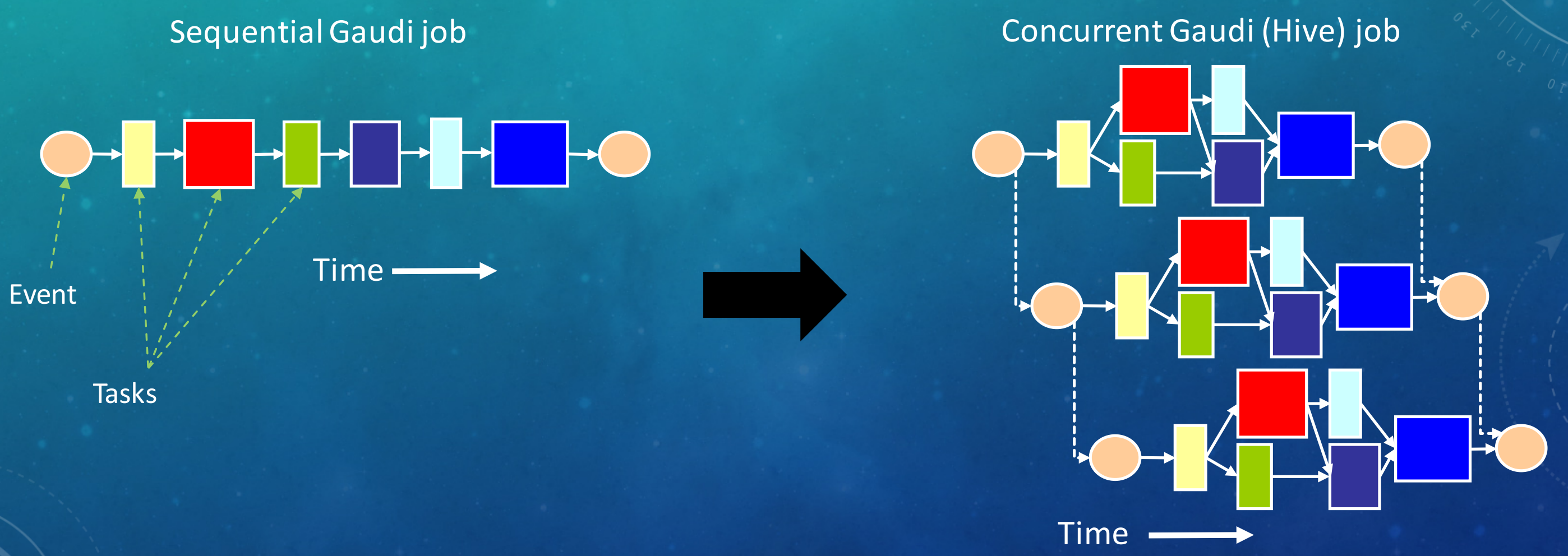


\section{CONCURRENT GAUDI (A.K.A. GAUDI HIVE)}

A prototype of a multithreaded task-based incarnation of Gaudi.
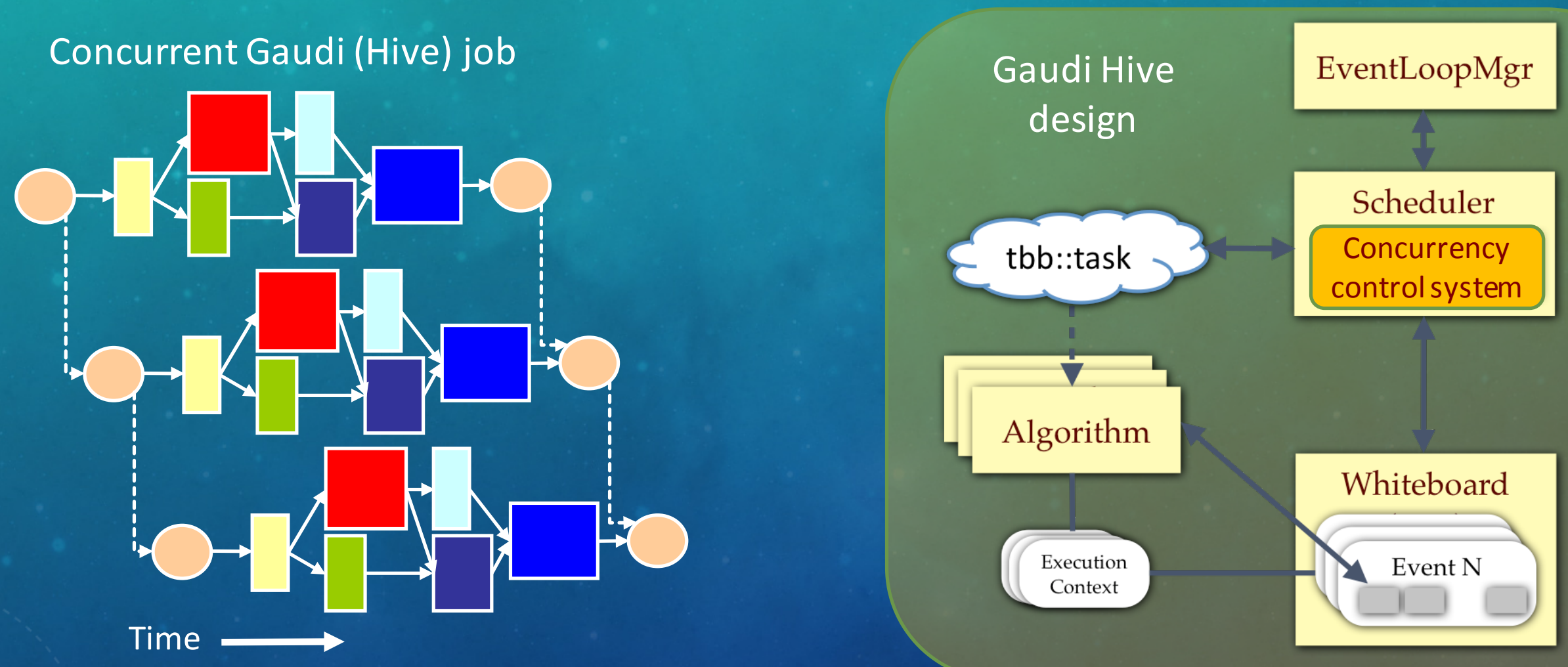


\section{GAUDI HIVE CONCURRENCY CONTROL}

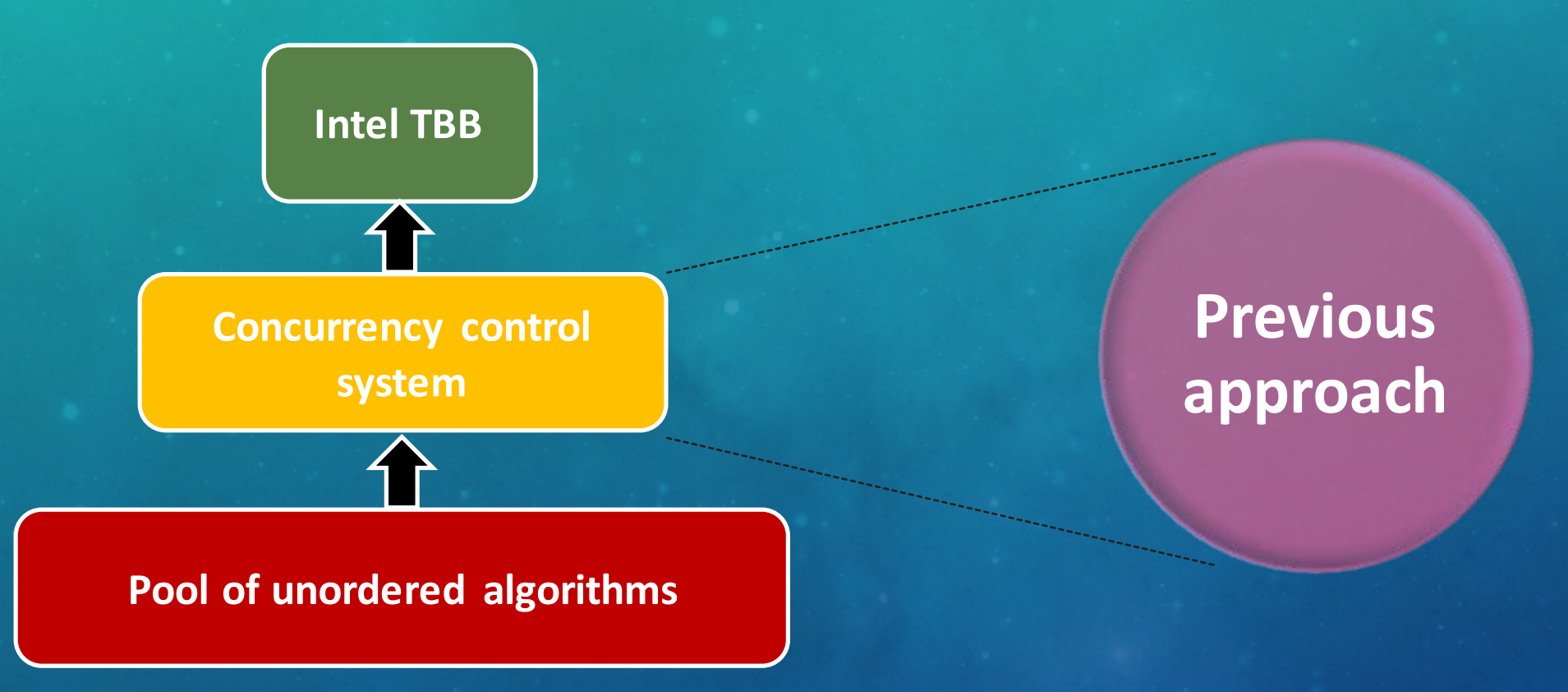




\section{GAUDI HIVE CONCURRENCY CONTROL}

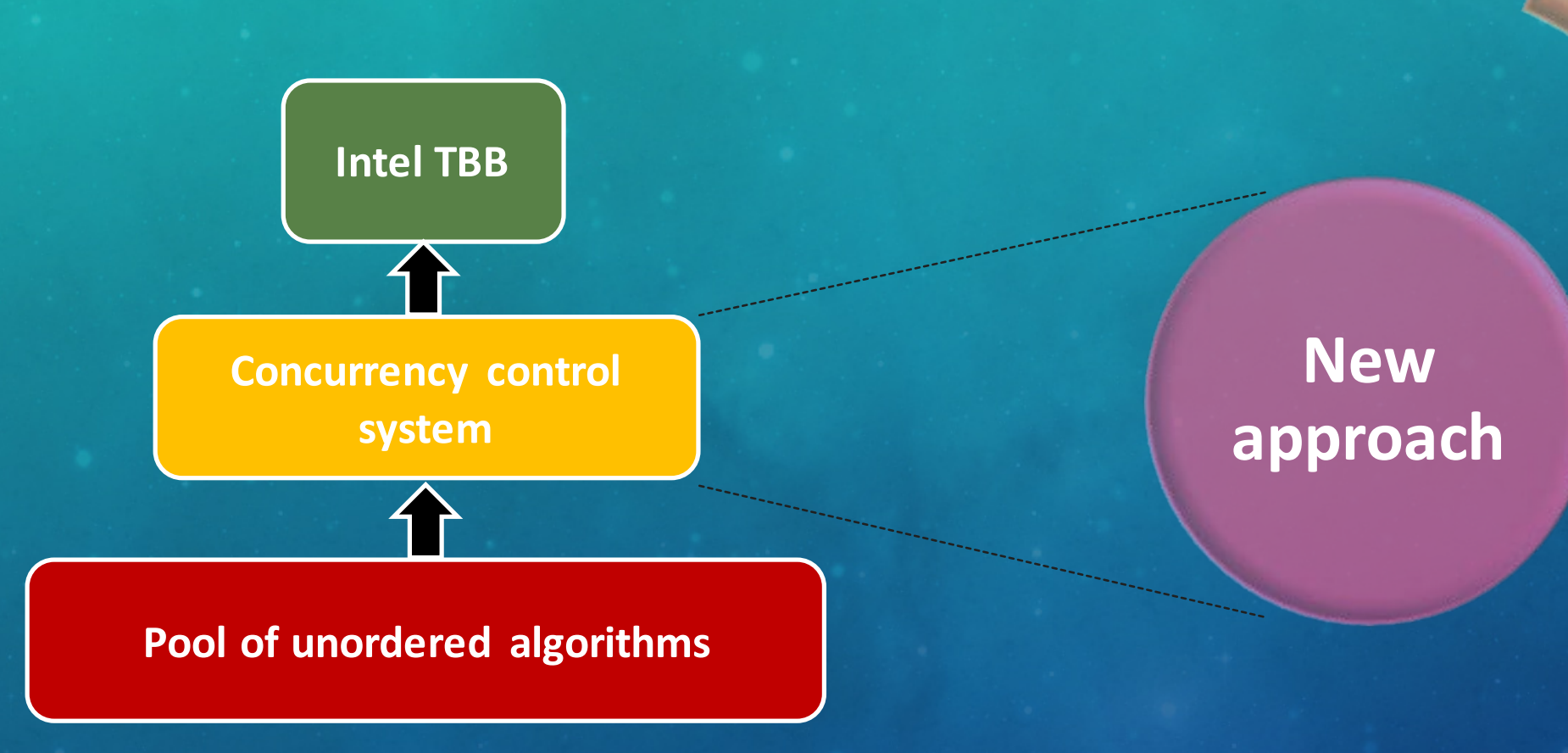

Reactive scheduling

Predictive scheduling

Automatic constraints analysis 


\section{INTRA-EVENT TASK PRECEDENCE RULES}

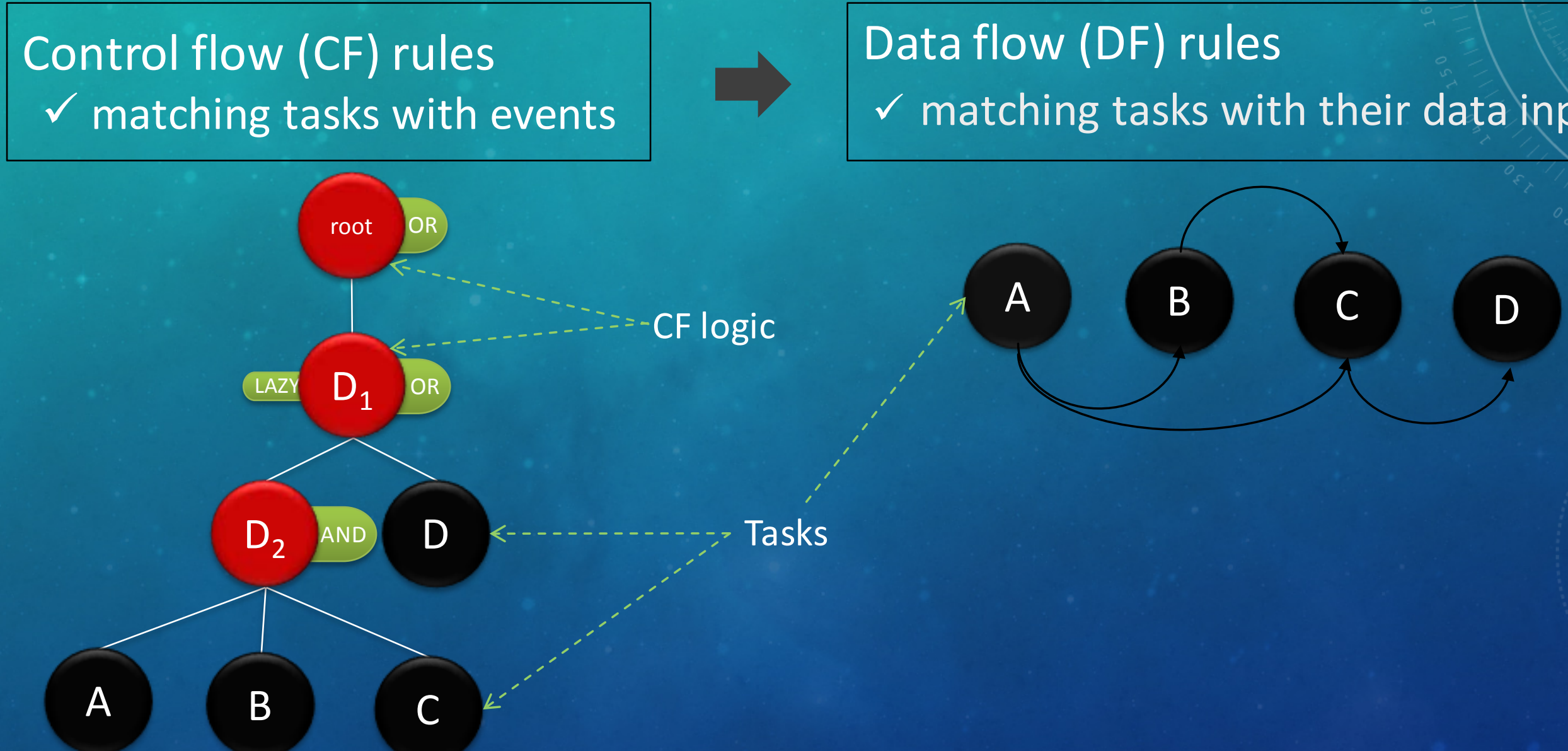




\section{GAUDI HIVE: FINITE STATE MACHINE}

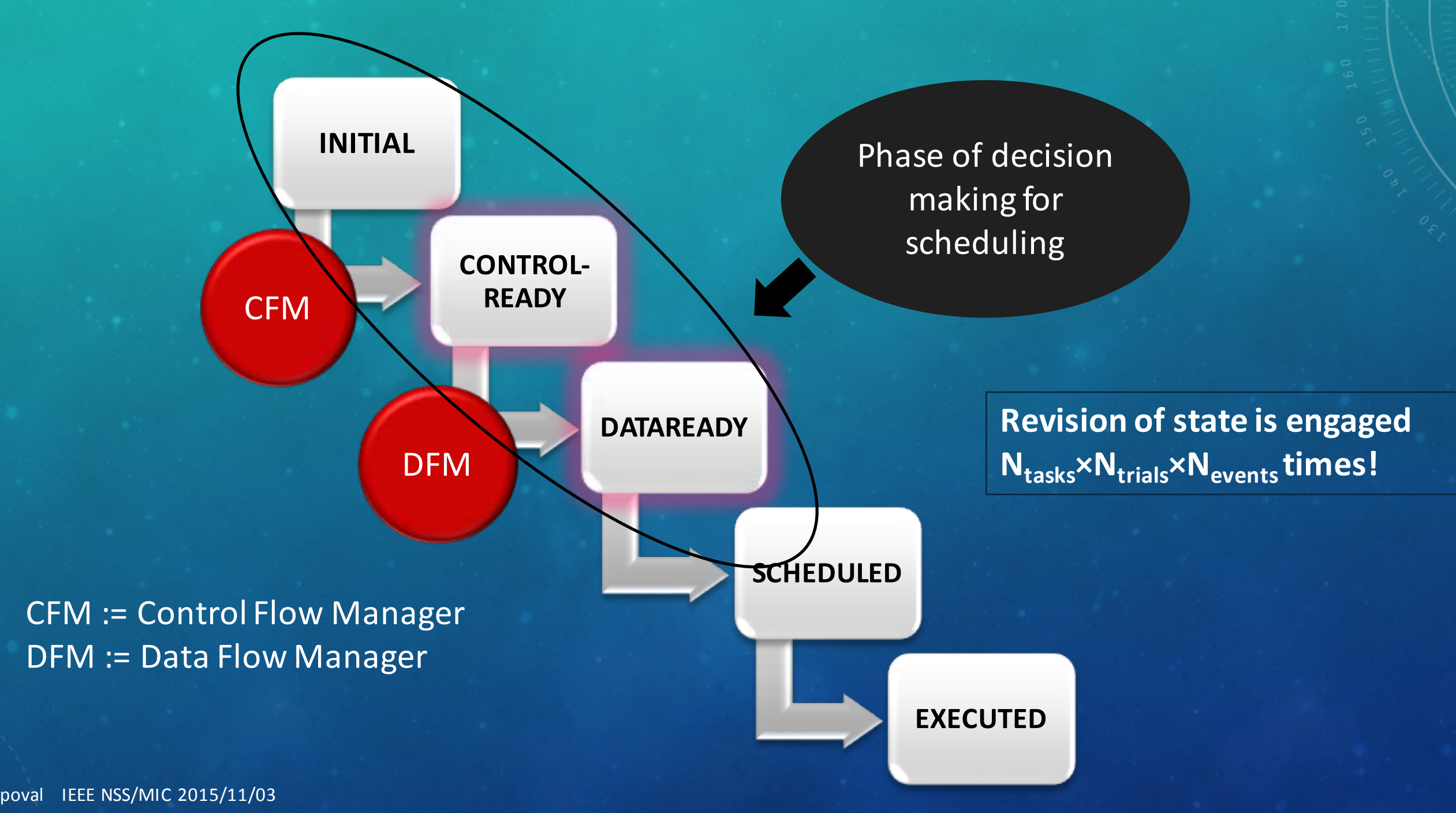




\section{DECISION MAKING IN SCHEDULING}

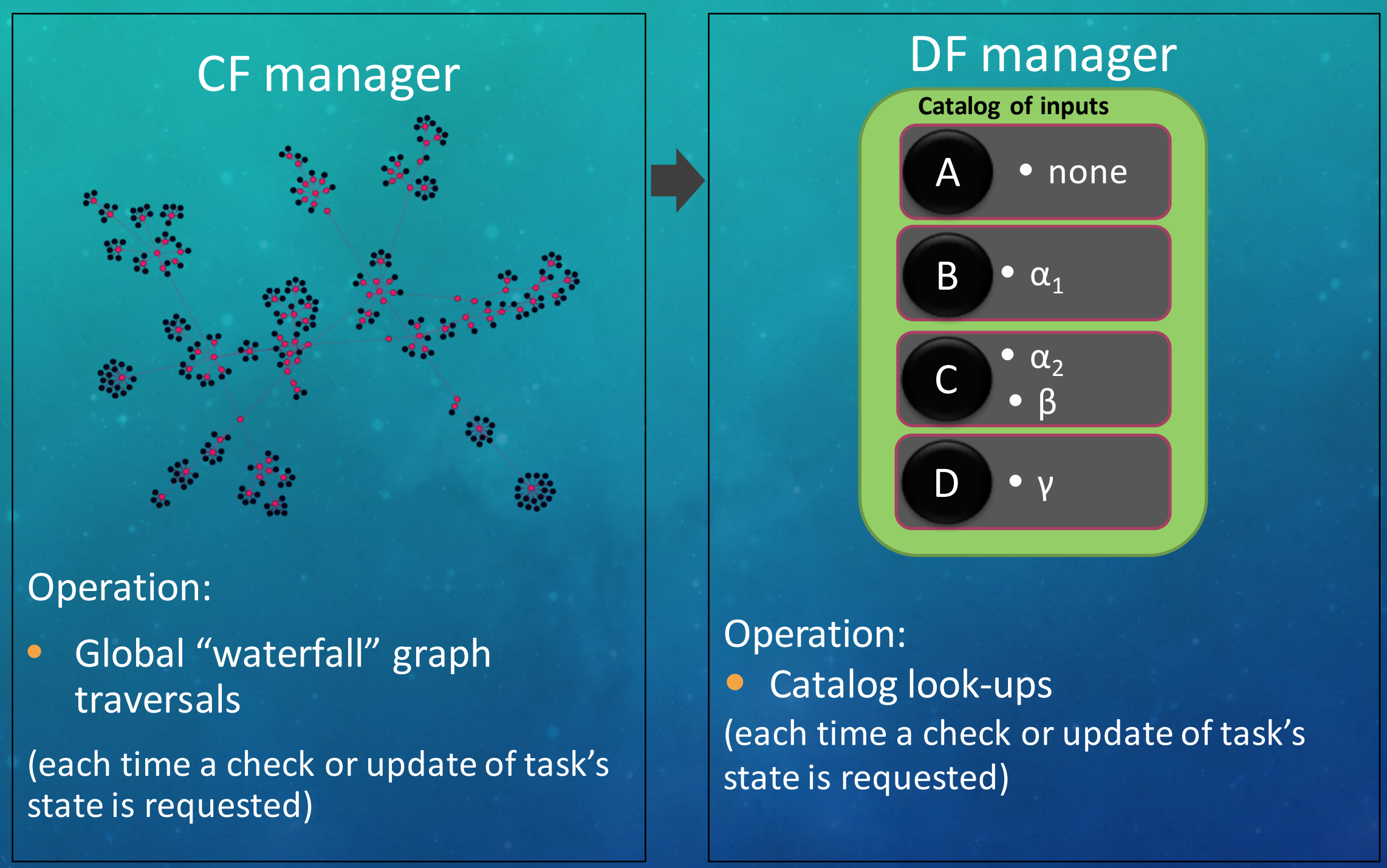




\section{DECISION MAKING IN SCHEDULING}
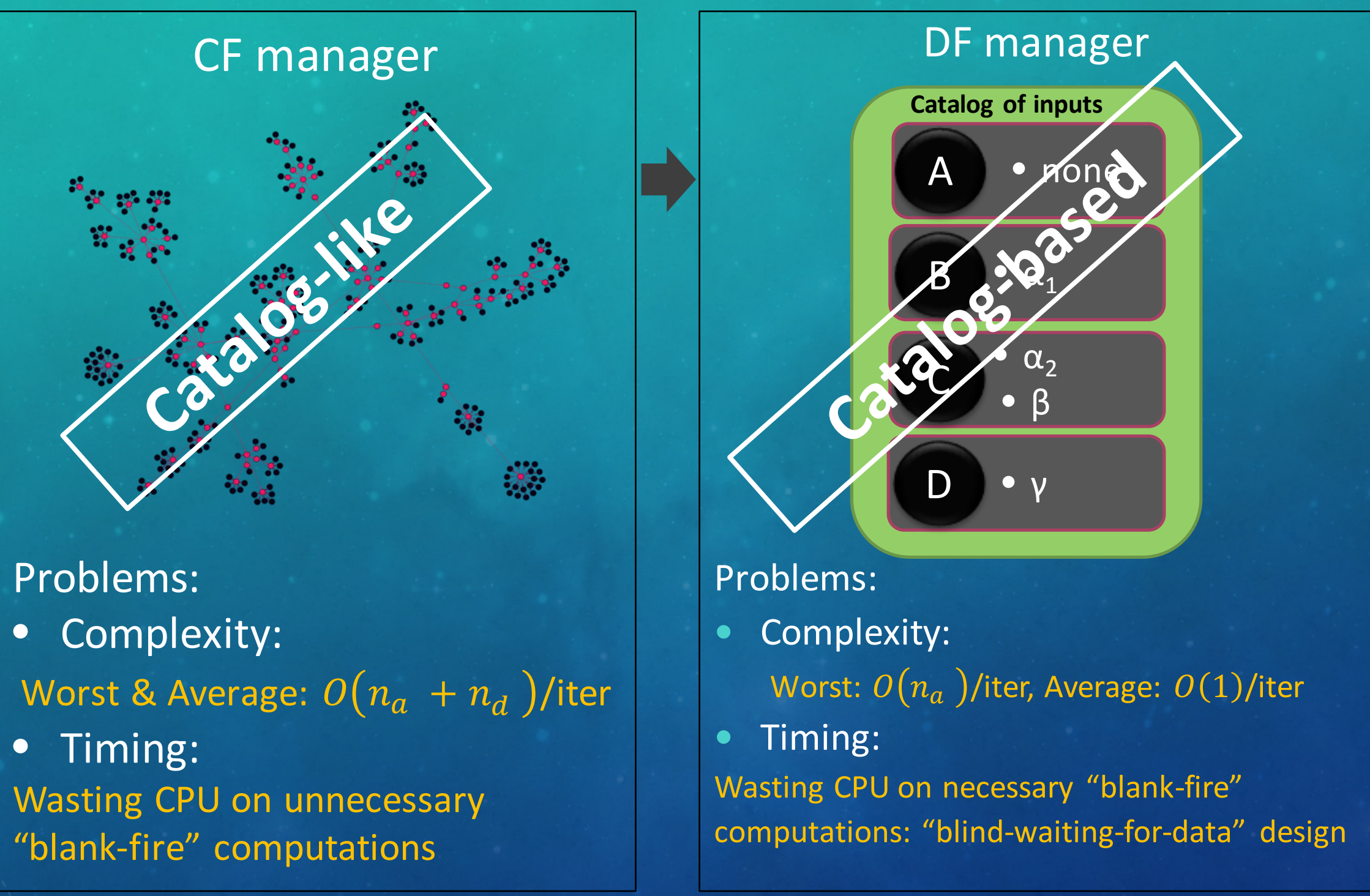


\section{DECISION MAKING IN SCHEDULING}

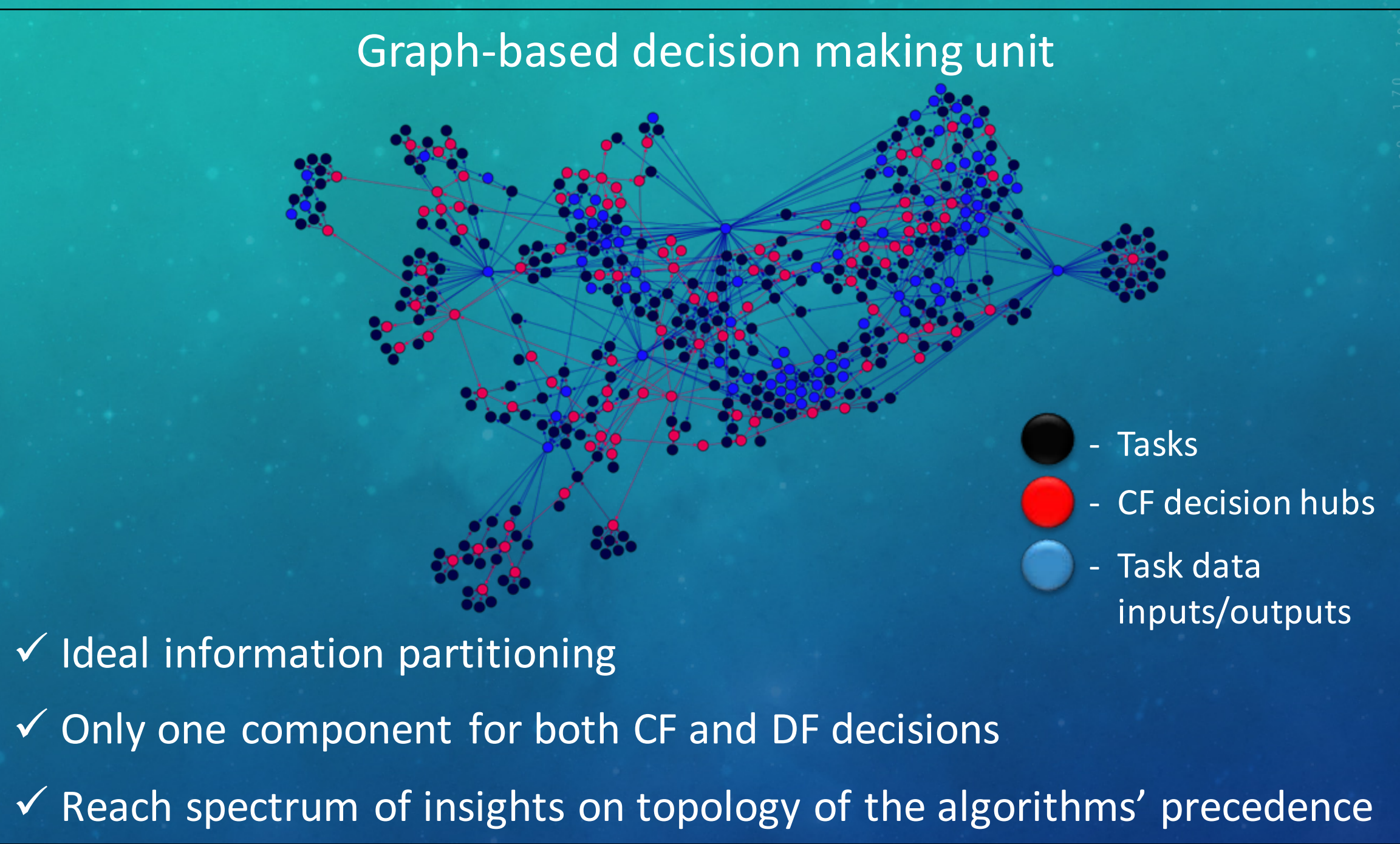




\section{DECISION MAKING COMPLEXITY}

\section{CF decisions DF decisions}

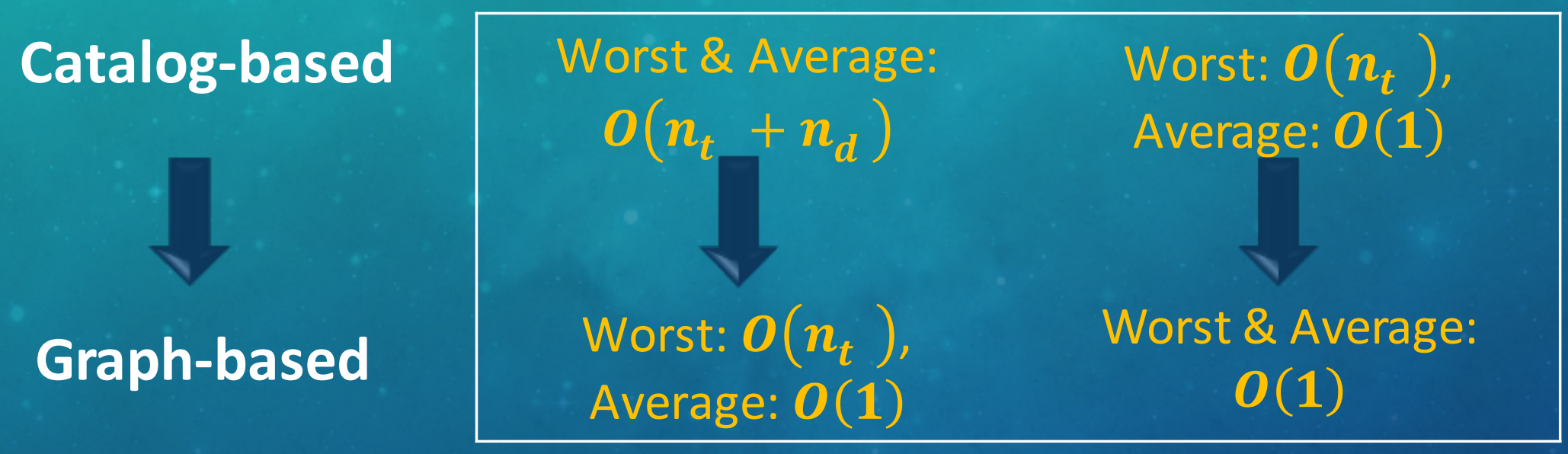

$$
\begin{aligned}
& n_{t}-\text { number of tasks } \\
& n_{d} \text { - number of decision hubs }
\end{aligned}
$$




\section{TIME OF DECISION MAKING}

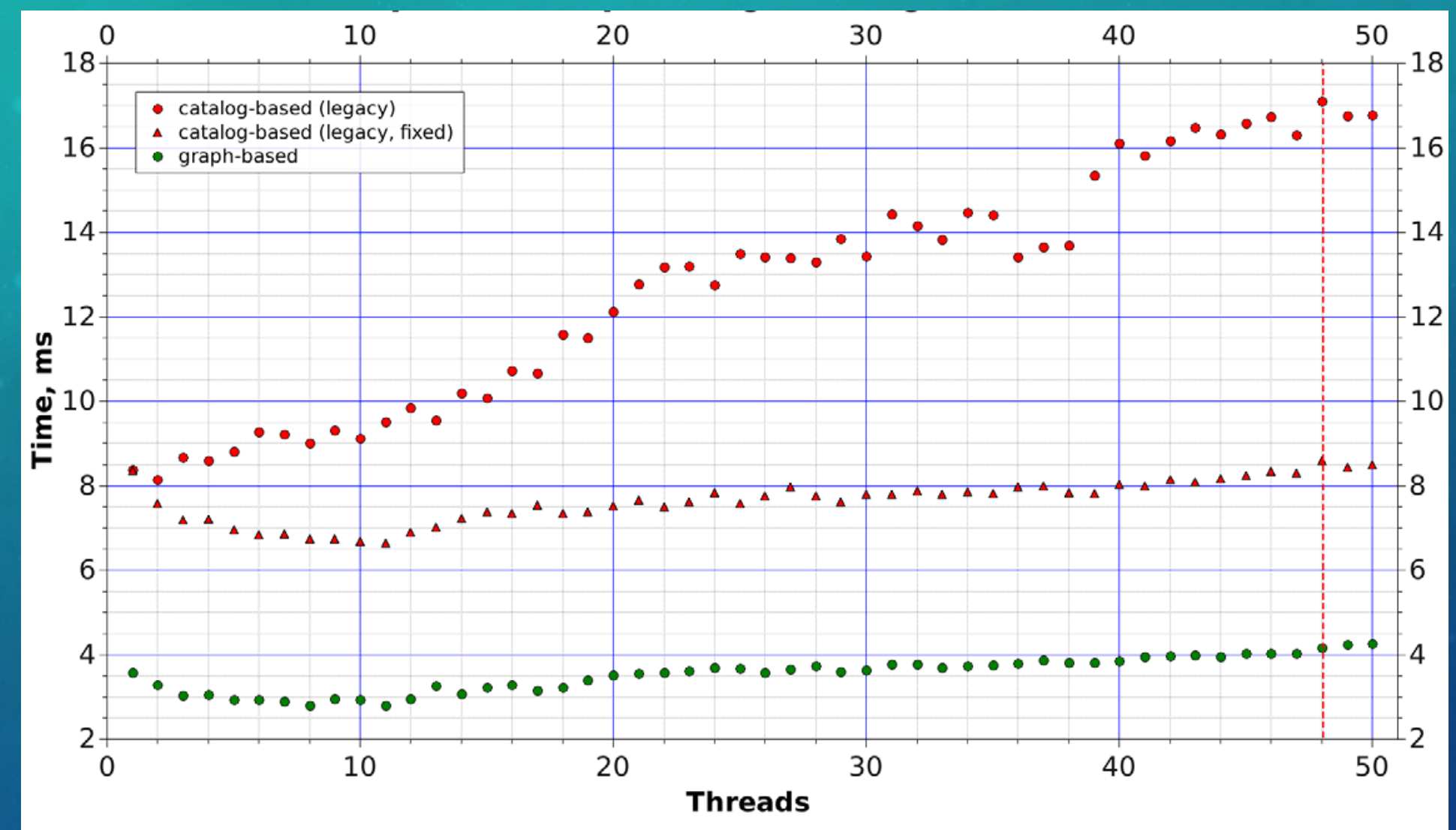

Total time spent to reason about precedence rules per event (spans 263 tasks) 


\section{CONTENT}

- Introduction

- Concurrency control: reactive scheduling

- Speedup and sc a la bility w ith rea c tive sched uling

- Concurrency control: predictive scheduling

- Generic a nalysis of speed up co nstra ints 


\section{SPEEDUP SATURATION: OPTIMISTIC TASK TIMING MAP}

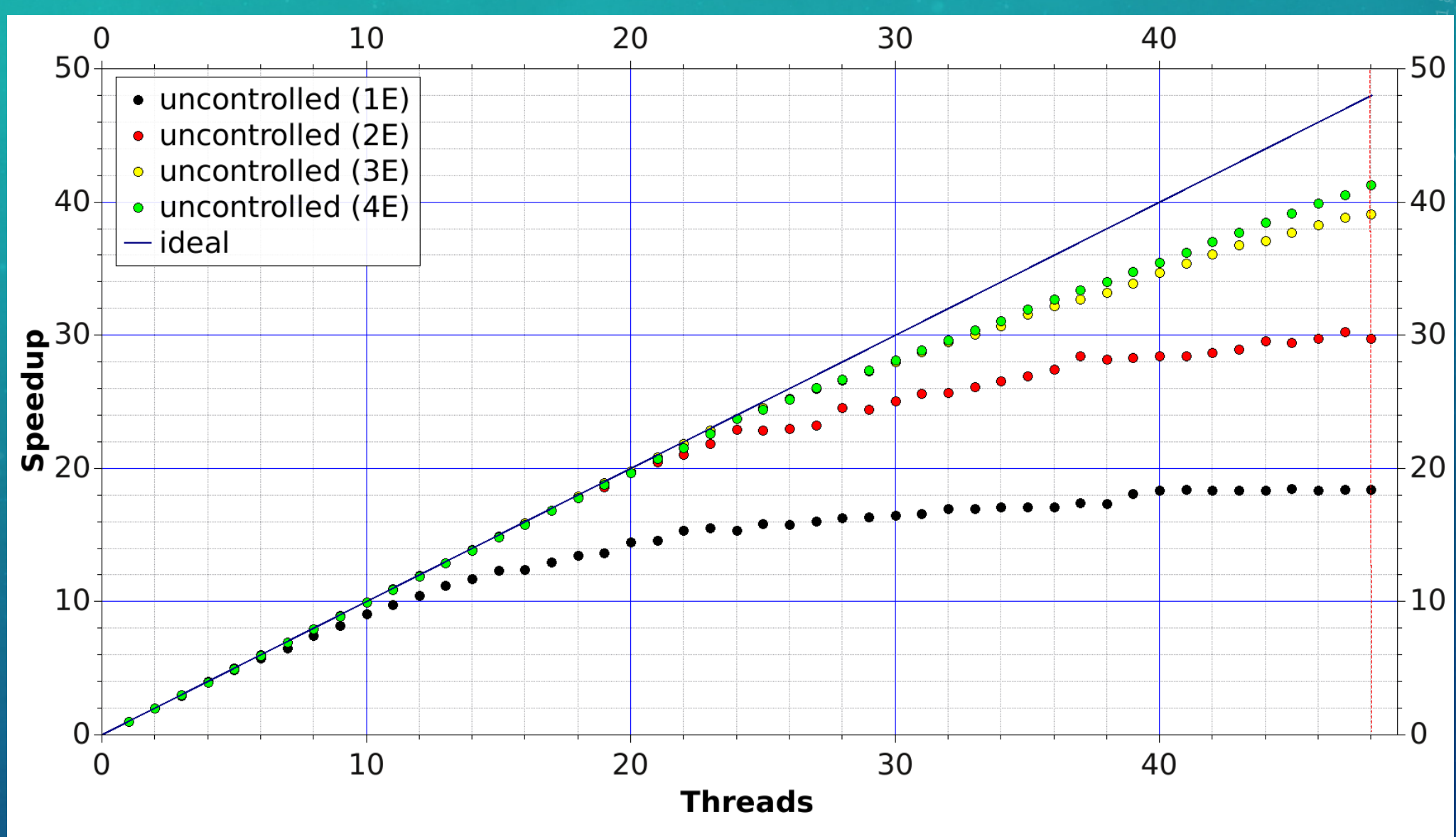

Intra-event + inter-event mode (uniform task timing 10ms) 


\section{SPEEDUP SATURATION:PESSIMISTIC TASK TIMING MAP}

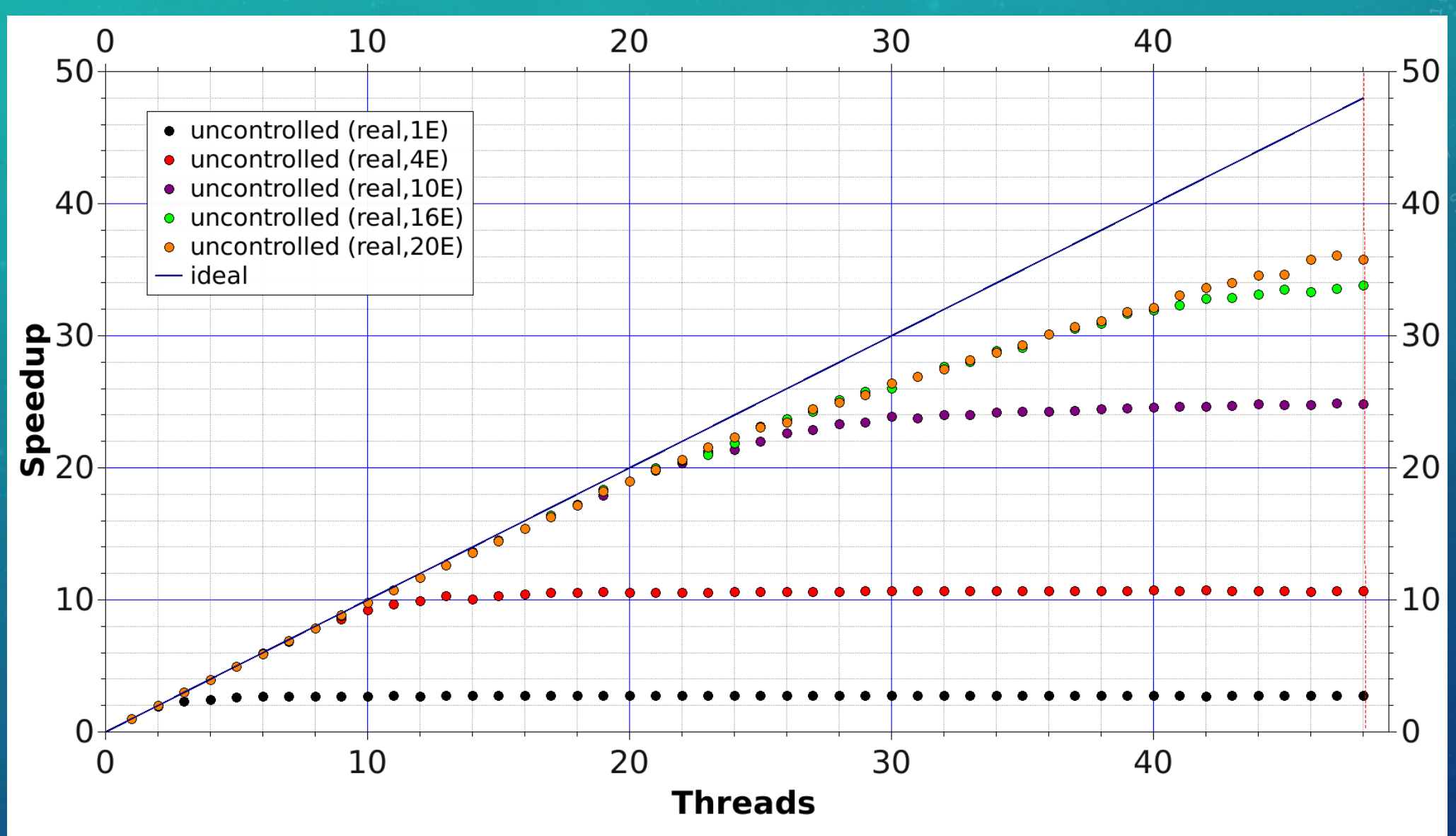

Intra-event + inter-event mode (real task timing) 


\section{WAYS TO FACILITATE SCALABILITY}

- Further reduce framework-level overhead (not discussed in this talk) 


\section{WAYS TO FACILITATE SCALABILITY}

- Further reduce framework-level overhead (not discussed in this talk)

- Improve intra-event concurrency dynamics

- its low level pushes to overuse the inter-event concurrency

- may help to better utilize data locality 


\section{INTRA-EVENT CONCURRENCY DYNAMICS}

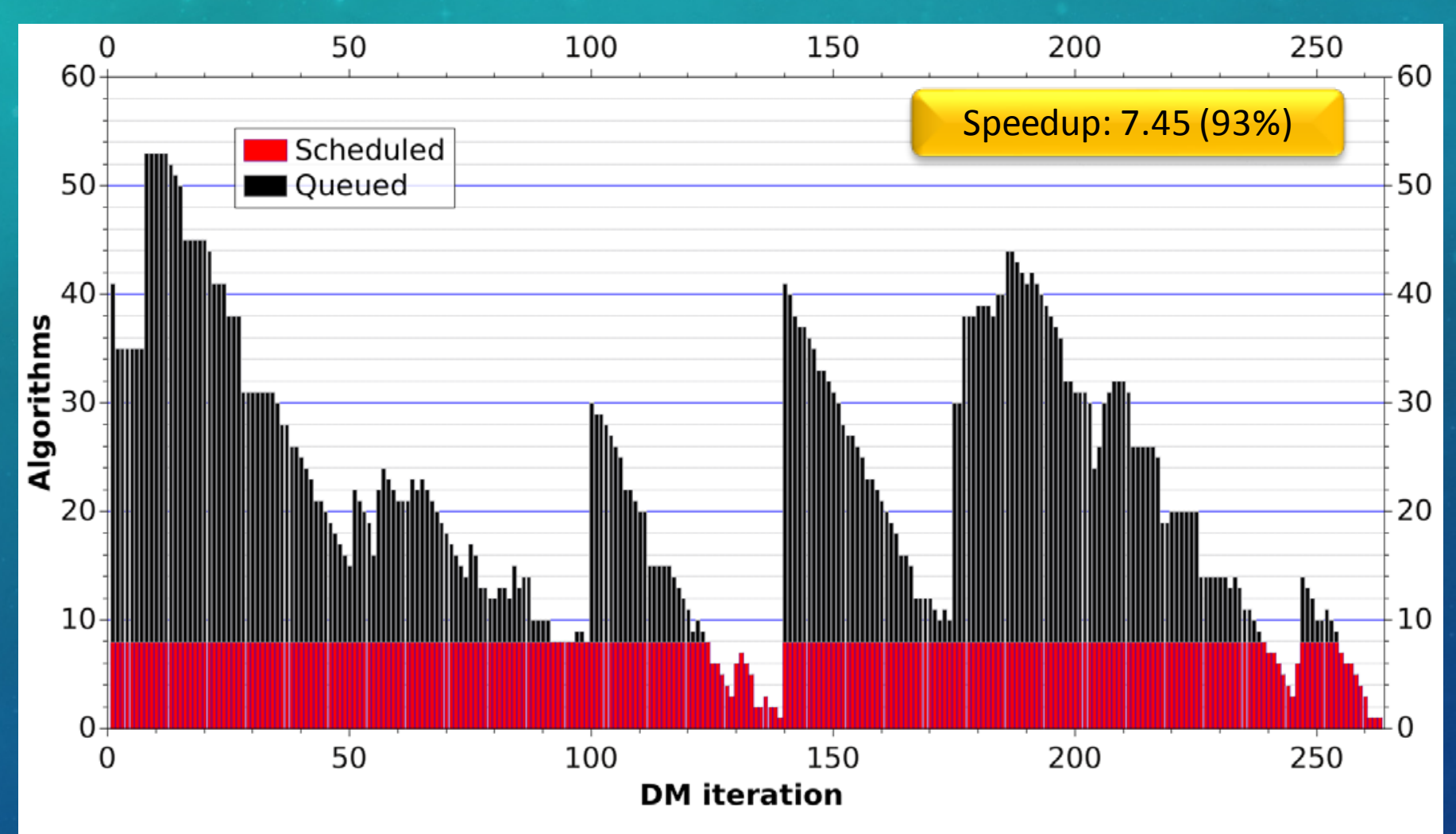

Reactive scheduling only (8 threads, 263 tasks per event) 


\section{INTRA-EVENT CONCURRENCY DYNAMICS}

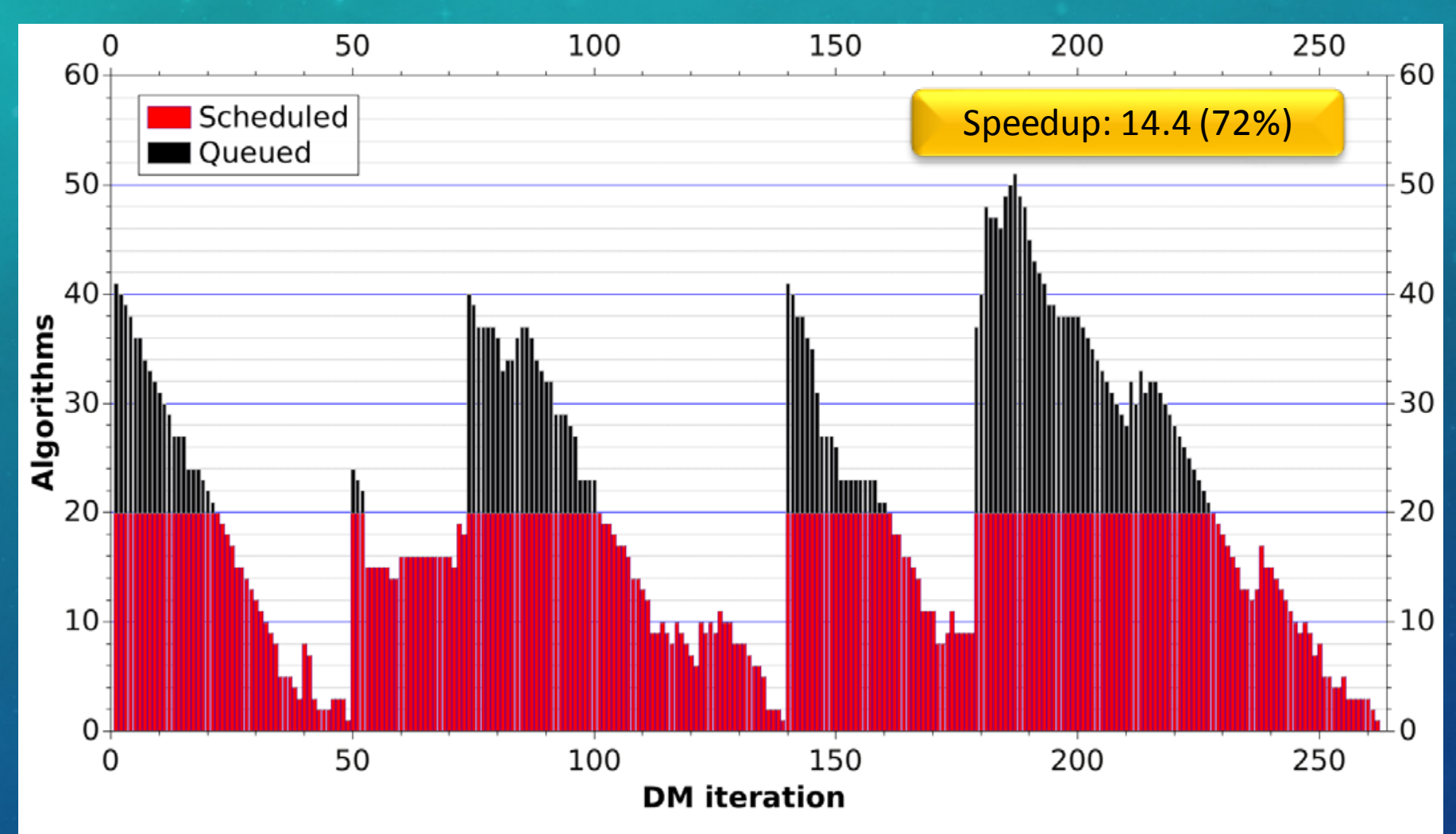

Reactive scheduling only (20 threads, 263 tasks per event) 


\section{HARMFUL DEGREES OF FREEDOM $\ldots$}

- Typical task precedence graphs (in LHCb) are significantly heterogeneous

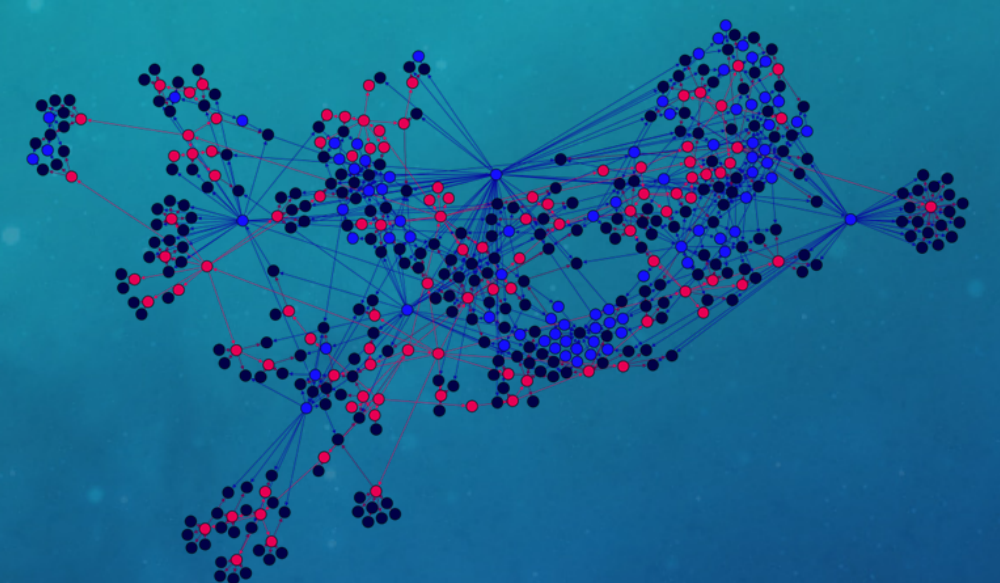

- Concurrency disclosure dynamics is drastically dependent on execution front

- uncontrolled in Gaudi Hive minimalistic reactive scheduling 


\section{CONTENT}

- Introduction

- Concurrency control: reactive scheduling

- Speedup and scalability w ith reactive sc heduling

- Concurrency control: predictive scheduling

- G eneric a na lysis of sp ee dup co nstra ints 


\section{PREDICTIVE SCHEDULING IN GAUDI HIVE}

\section{What:}

- maximize concurrency disclosure dynamics

- or at least create facilitating pressure towards it How:

- rank algorithms reflecting their 'importance' within precedence graph

- plenty of ranking strategies studied elsewhere

- prioritize the queue of ready-to-run algorithms following each reactive iteration 


\section{ASYMMETRY OF PRODUCTS CONSUMPTION}

\section{Rank algorithm by its products consumption extent}

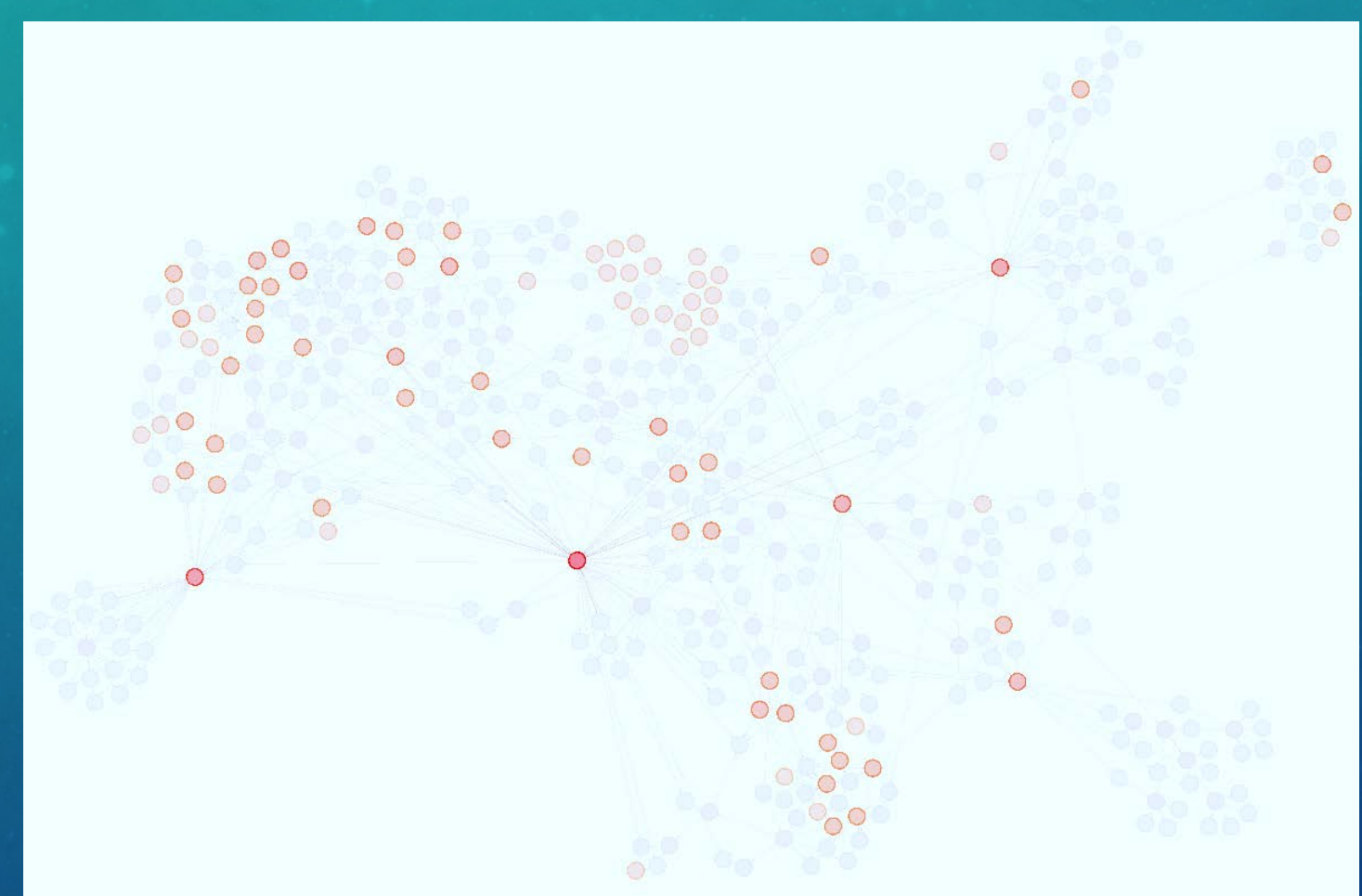

Precedence graph with all, but data nodes, faded out. Color intensity of a data node represents the number of its consumers 


\section{PREDICTIVE SCHEDULING: PRODUCTS CONSUMPTION EXTENT (PCE)}

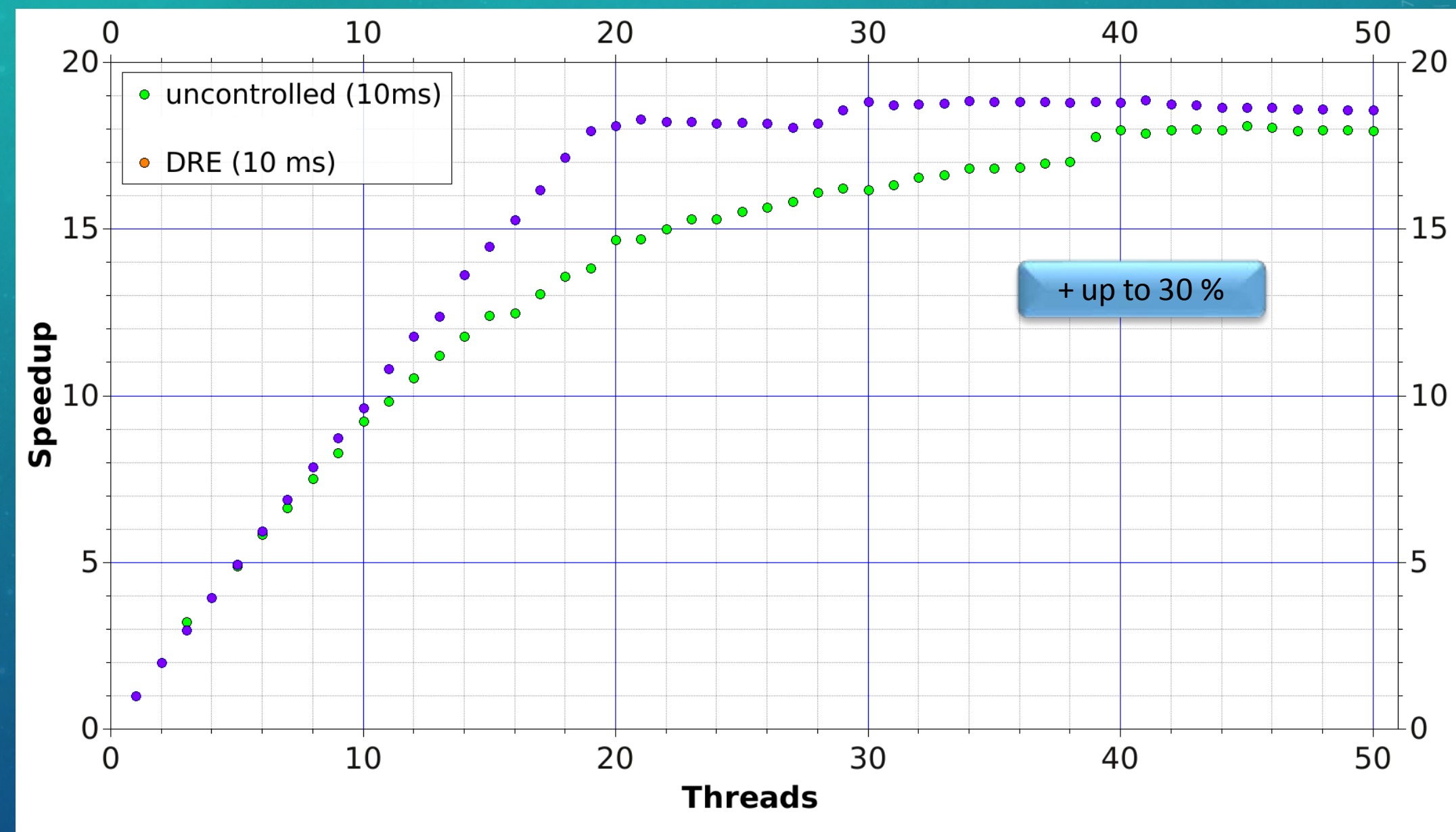

Uniform task timing map ( 10ms) 


\section{PREDICTIVE SCHEDULING: DATA REALM ECCENTRICITY (DRE)}

- rank algorithm by its eccentricity in data realm

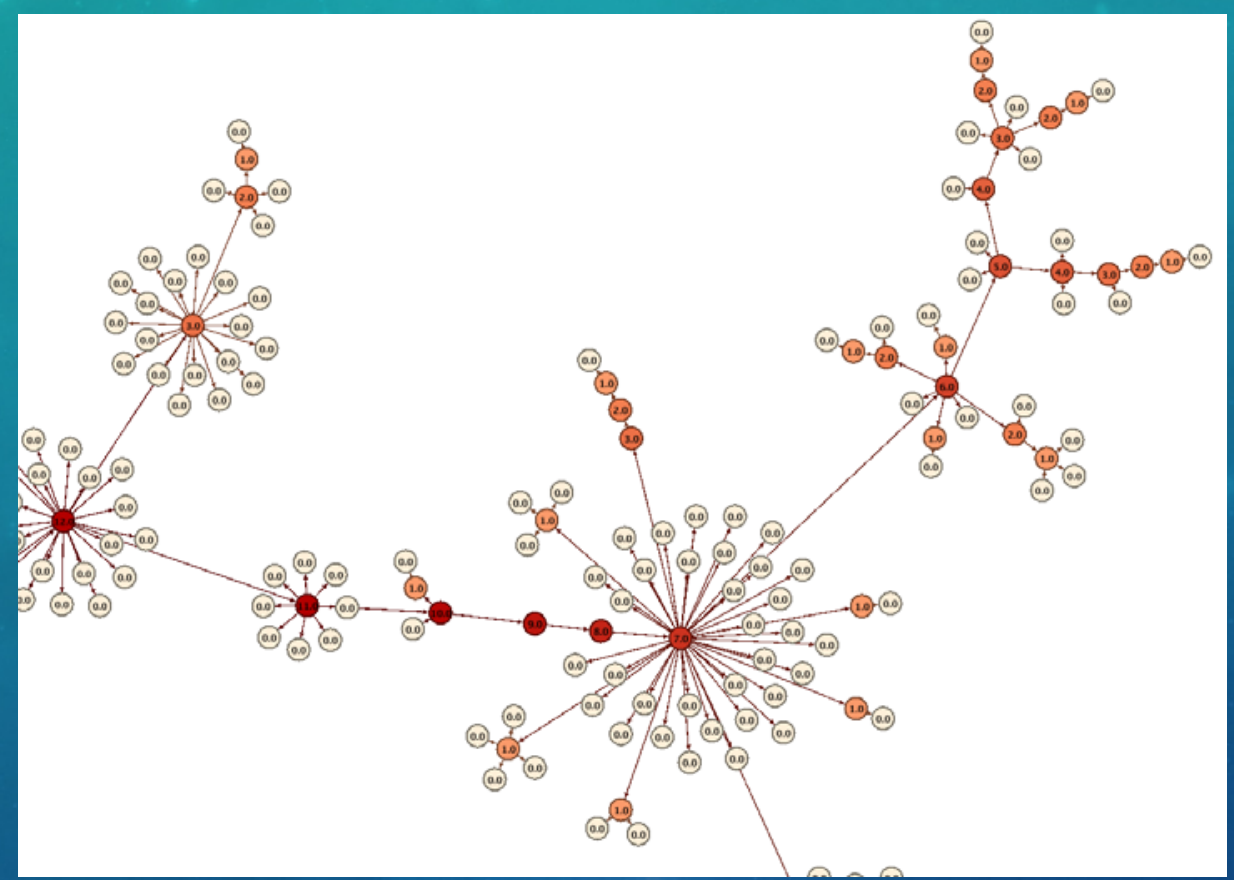

Color intensity represents eccentricity-based rank

- implements critical path lookup technique in case of uniform task timing map

- note: not only graph diameter is tracked, but also all other sub-critical paths 


\section{PREDICTIVE SCHEDULING: DATA REALM ECCENTRICITY (DRE)}

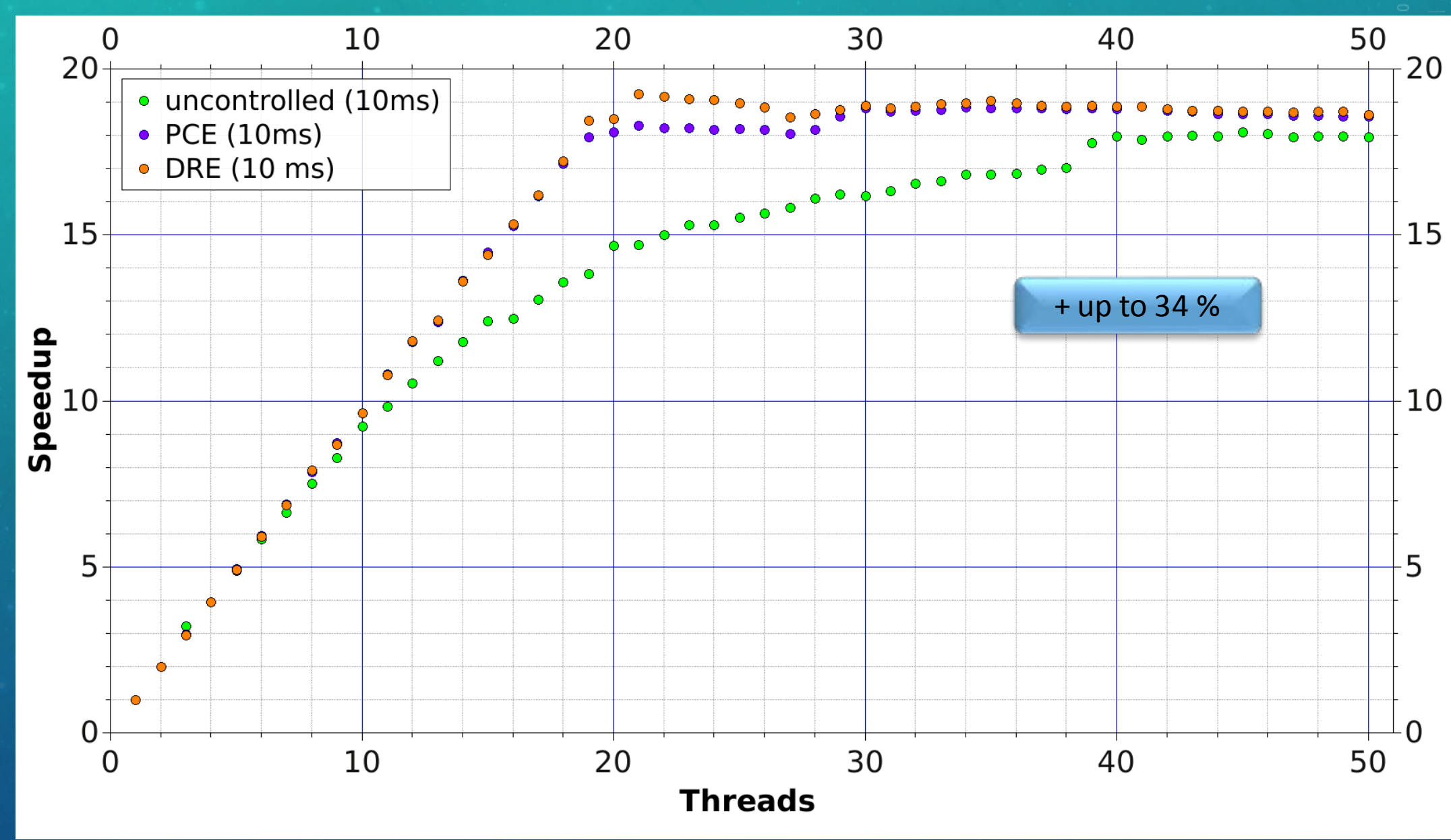

Uniform task timing map ( 10ms) 


\section{PREDICTIVE SCHEDULING: DRE MODE}
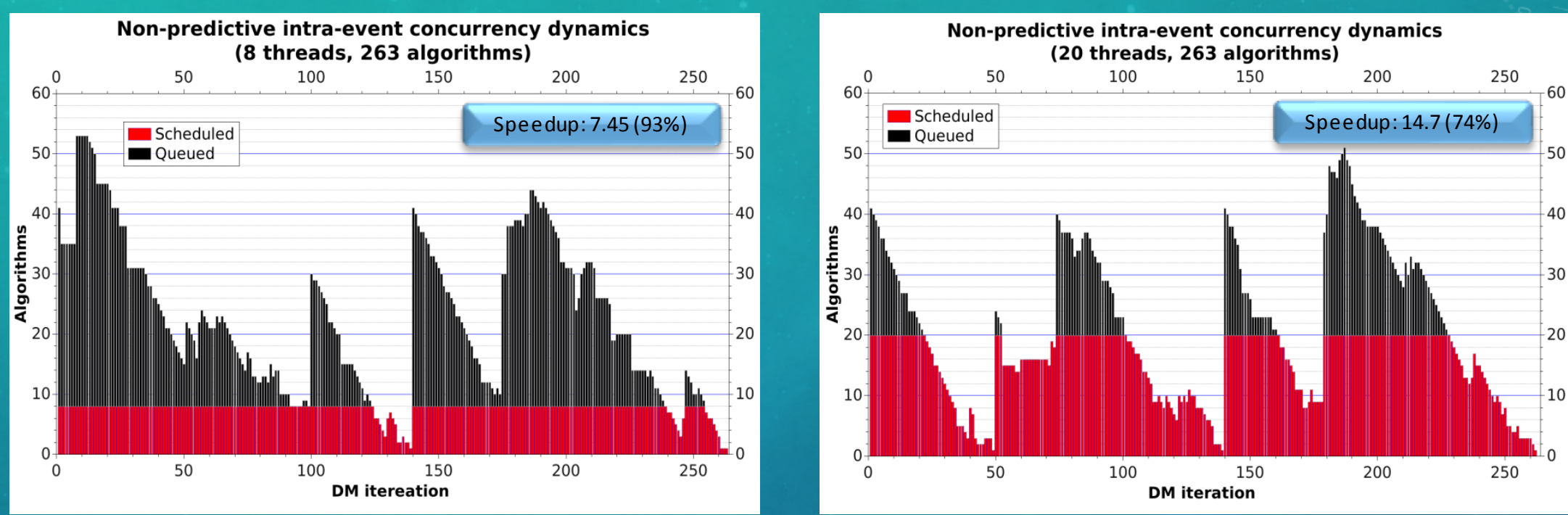


\section{PREDICTIVE SCHEDULING: DRE MODE}
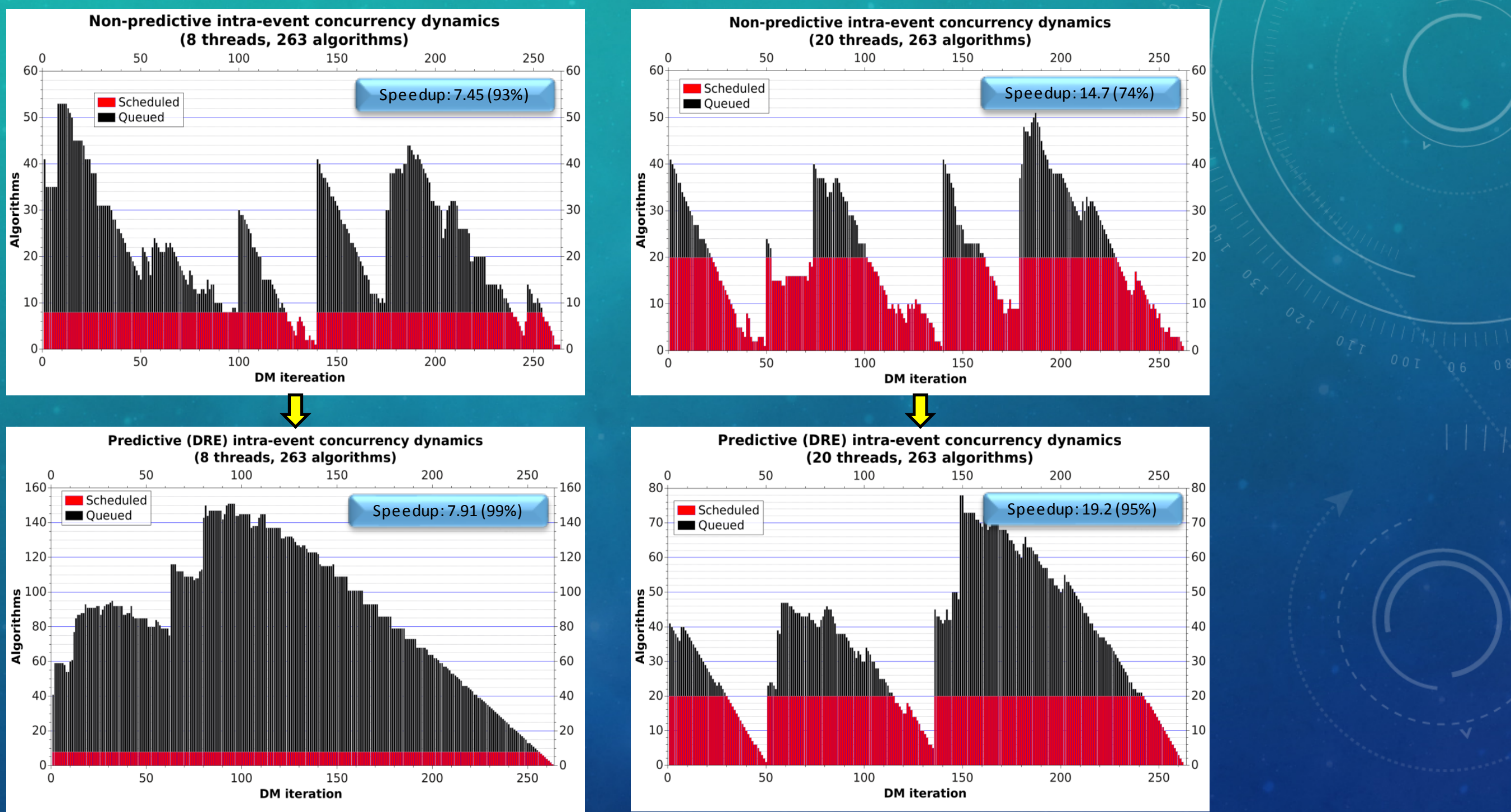


\section{SPEEDUP SATURATION IN PREDICTIVE SCHEDULING}

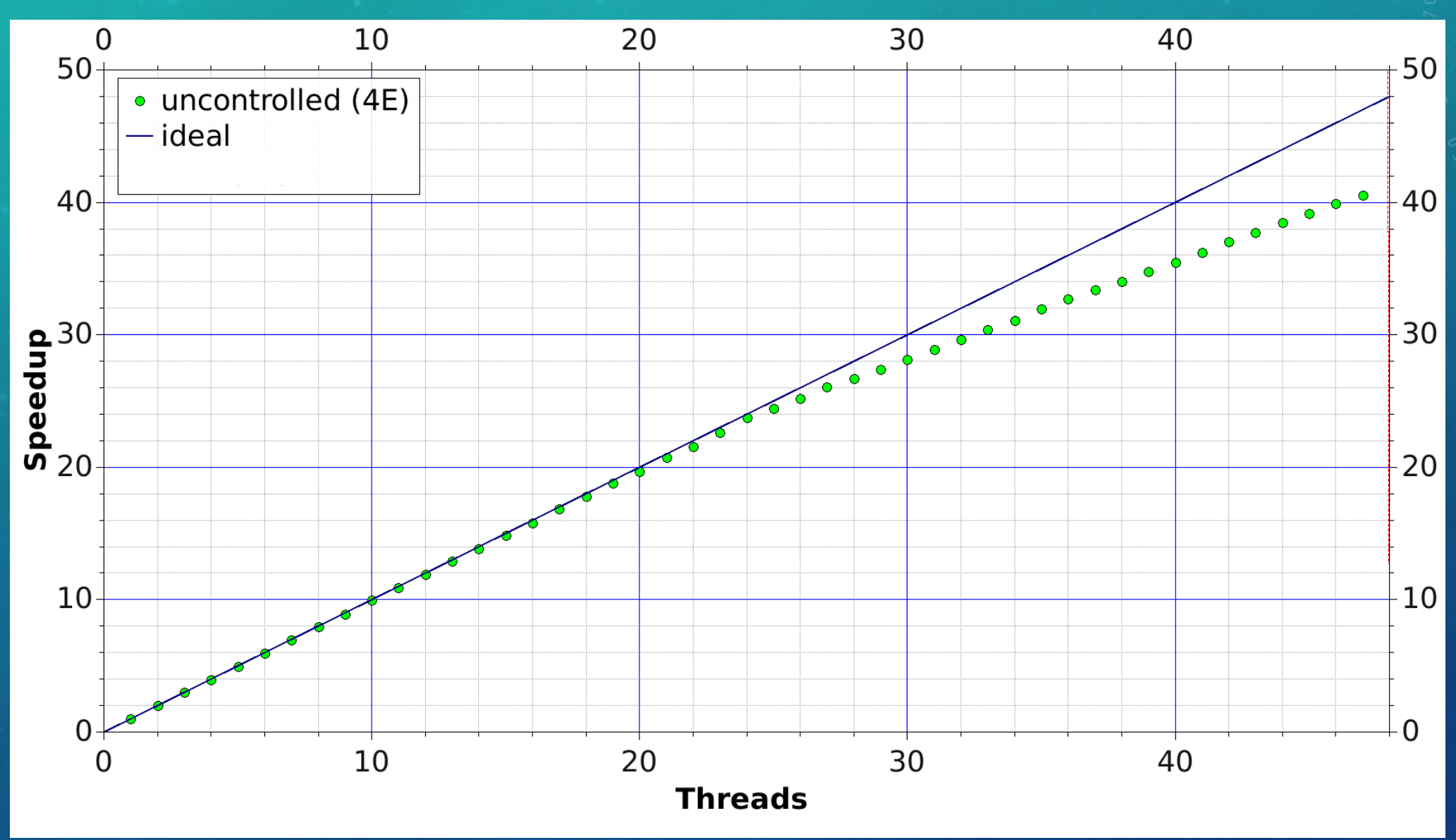

Intra-event + inter-event mode (uniform task timing map, 10ms) 


\section{SPEEDUP SATURATION IN PREDICTIVE SCHEDULING}

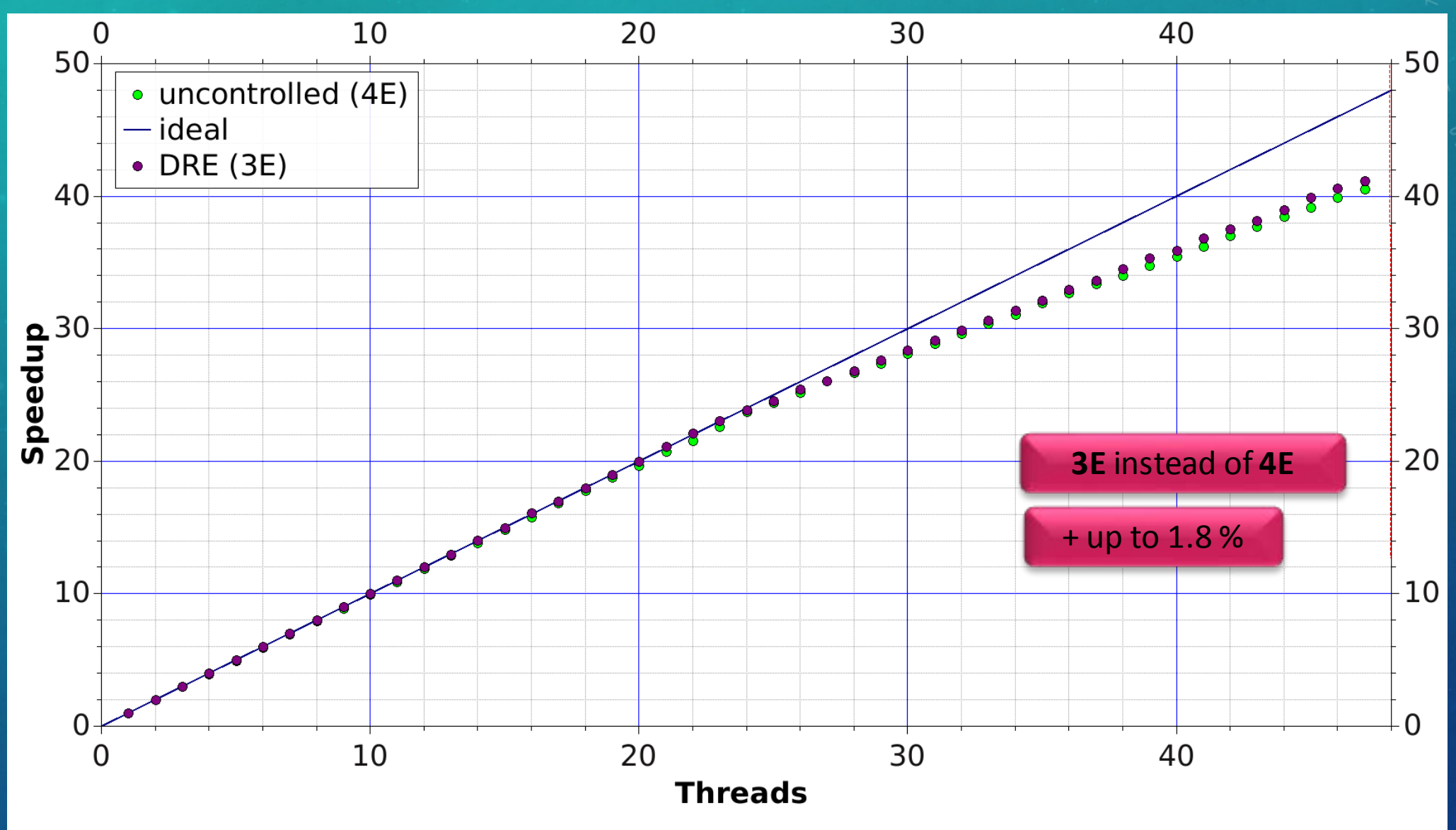

Intra-event + inter-event mode (uniform task timing map, 10ms) 


\section{CONTENT}

- Introduction

- Concurrency control: reactive scheduling

- Speedup and scalability w ith reactive sc heduling

- Concurrency control: predictive scheduling

- Generic a nalysis of speed up constraints 


\section{GENERIC ANALYSIS OF PRECEDENCE CONSTRAINTS}

- built-in tool available to create materialized views of polymorphous precedence graphs

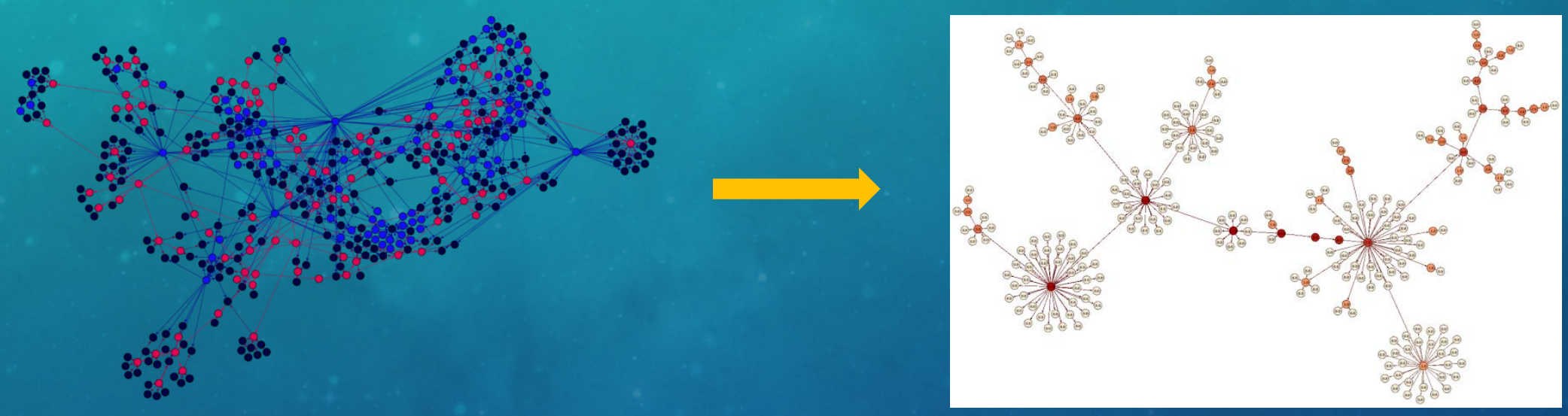

- provides, for a given event and hardware platform:

- visualization of critical and sub-critical paths

- theoretical intra-event speedup limit

- expertize on how to increase throughput in a given data processing workflow 


\section{CONCLUSION}

Graph-based decision making in concurrency control allows to:

- (Algorithmically) Reduce decision making time by $2 x$, and improve its asymptotic complexity

- Implement predictive scheduling with diverse look-ahead strategies, which:

- yield significant improvement in intra-event speedup ( $\sim 30 \%$ in $\mathrm{LHCb}$ event reconstruction workflow)

- allow to achieve higher throughput in harsh data processing conditions 


\section{SPARE SLIDES}




\section{TESTBED FOR BENCHMARKING}

- Intel(R) Xeon(R) CPU E5-2695 v2 @ 2.40GHz

- 2 sockets: $24+24 \mathrm{HT}$

- L2 256KB, L3 30 MB

Data processing workflow configuration:

- Precedence graph of close to real size and topology (LHCb Brunel reconstruction case)

- CPUCrunchers as tasks

- Real/uniform tasks' timings 


\section{RATIO OF DECISION MAKING TIME TO EVENT PROCESSING TIME}

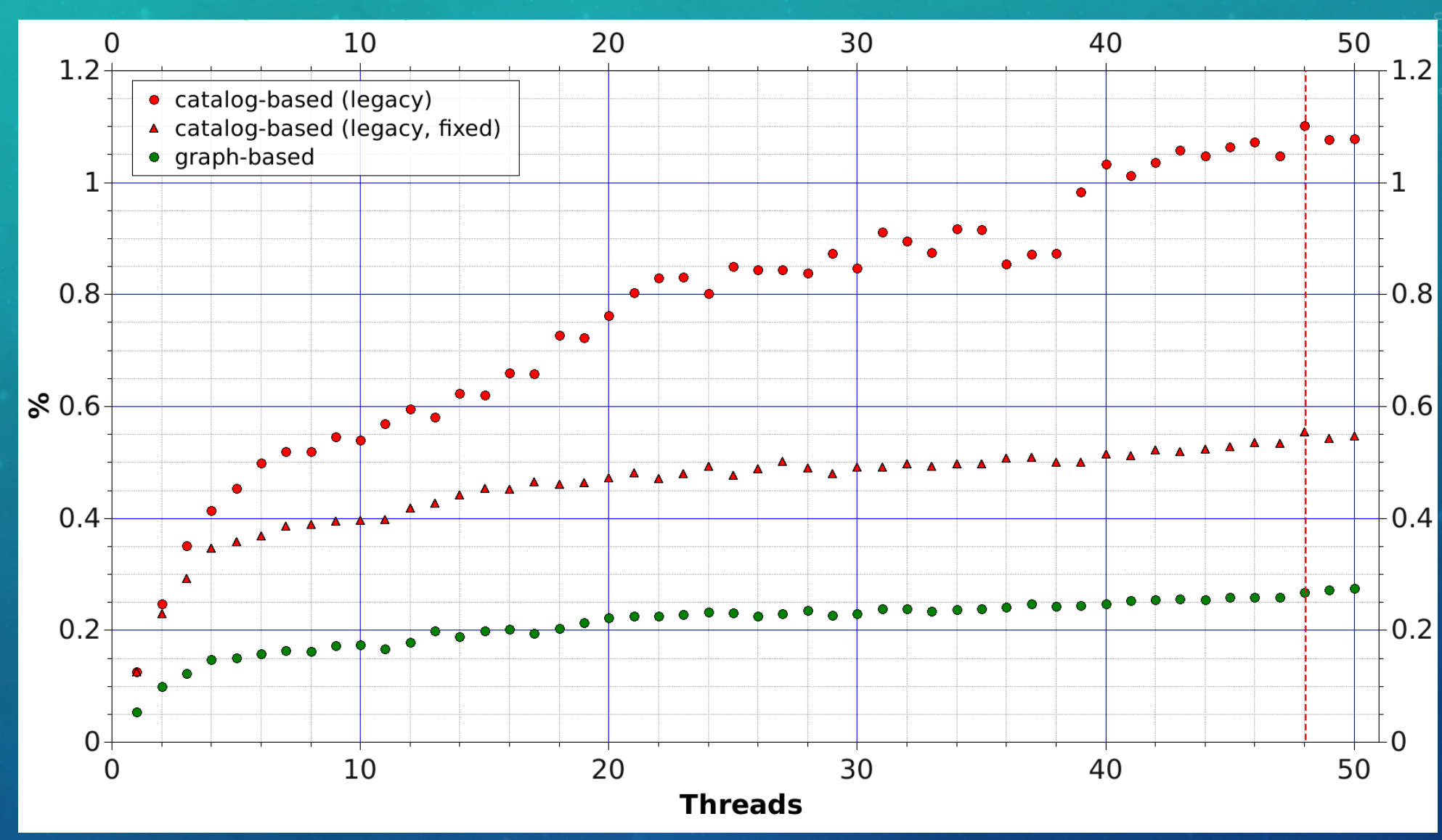

Chosen max. speedup of concurrent event processing is conservative: 


\section{SYSTEMATICS: ZERO MEASUREMENT}

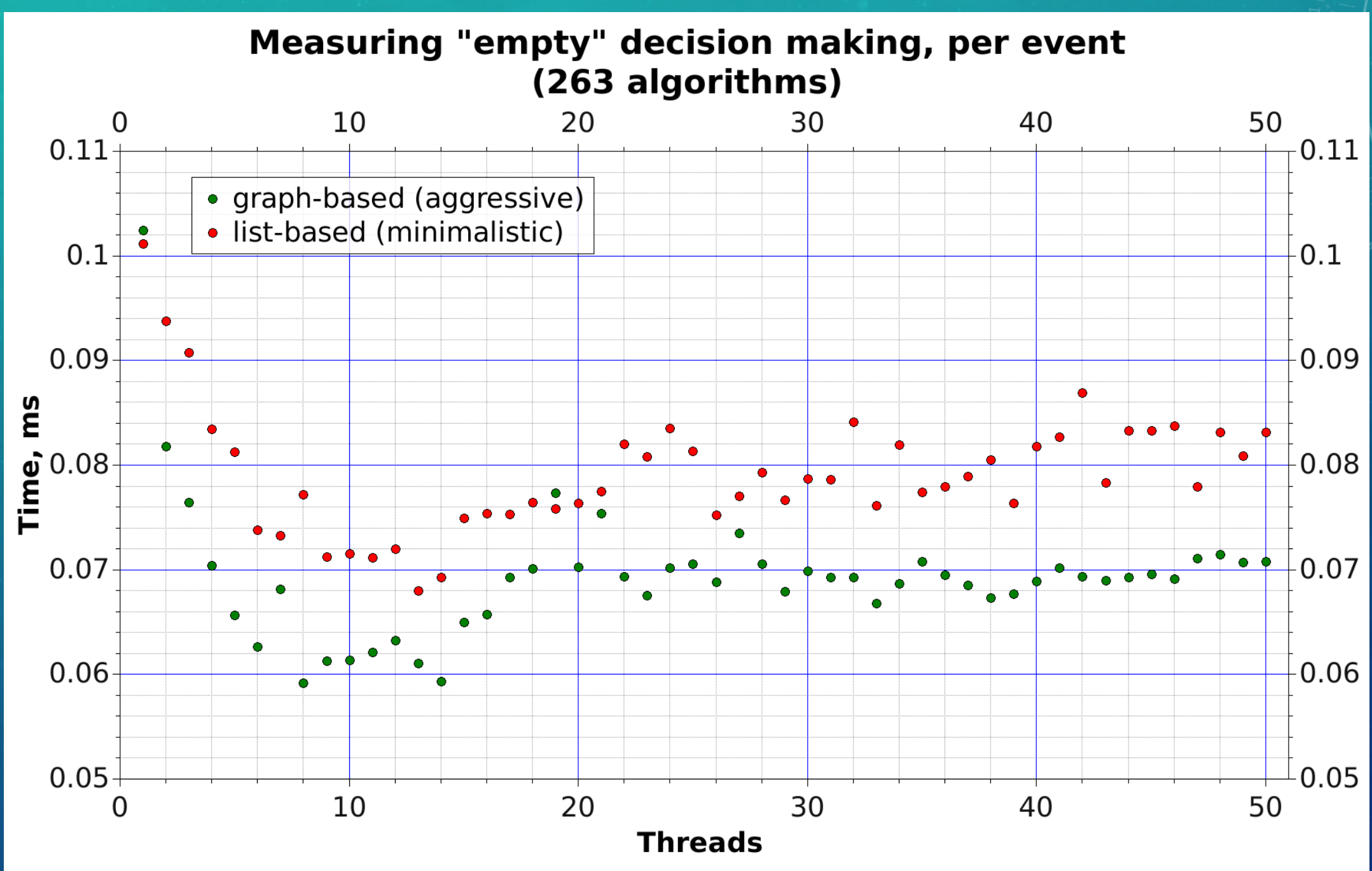




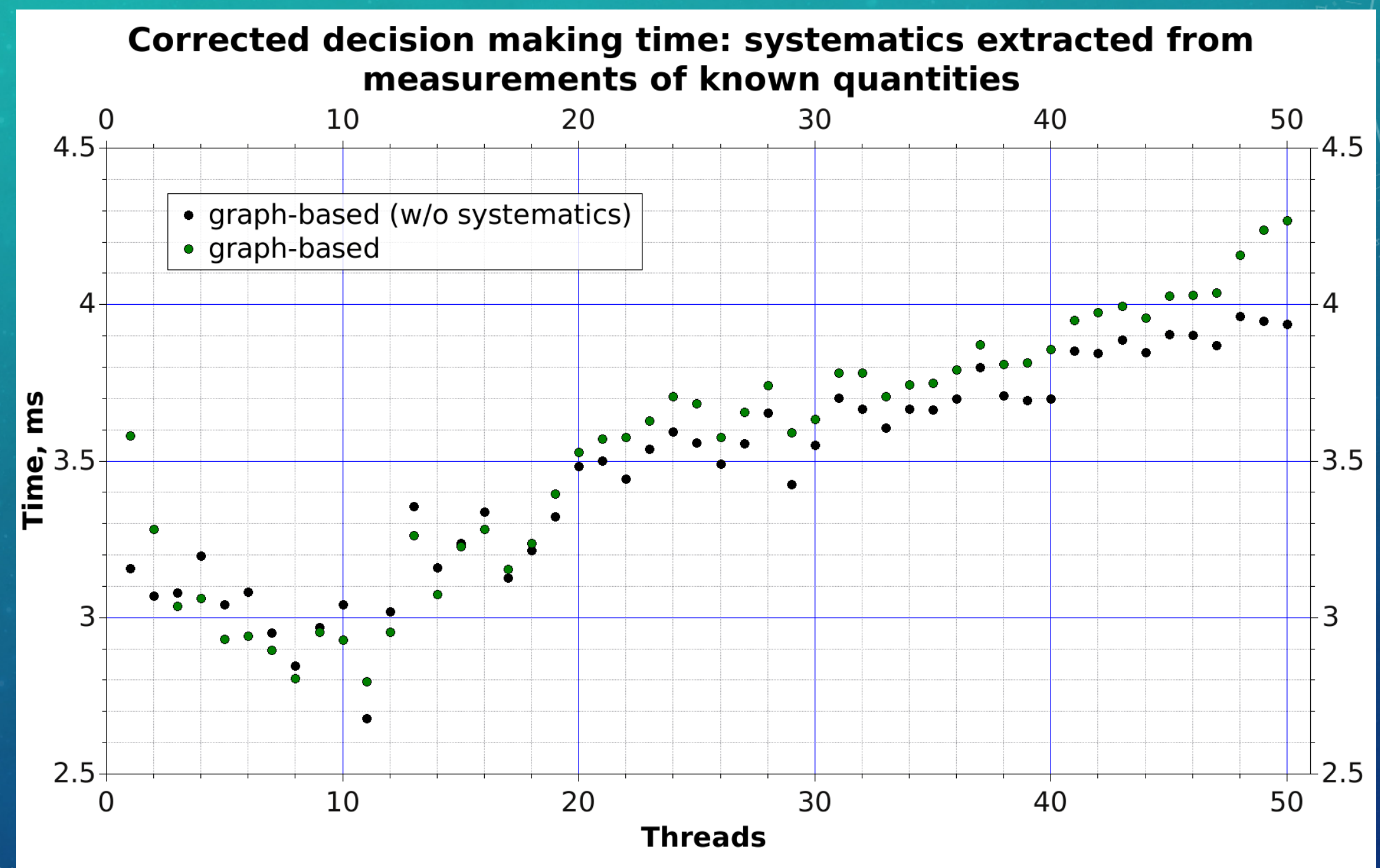




\section{RUNAWAY OF DECISION MAKING}

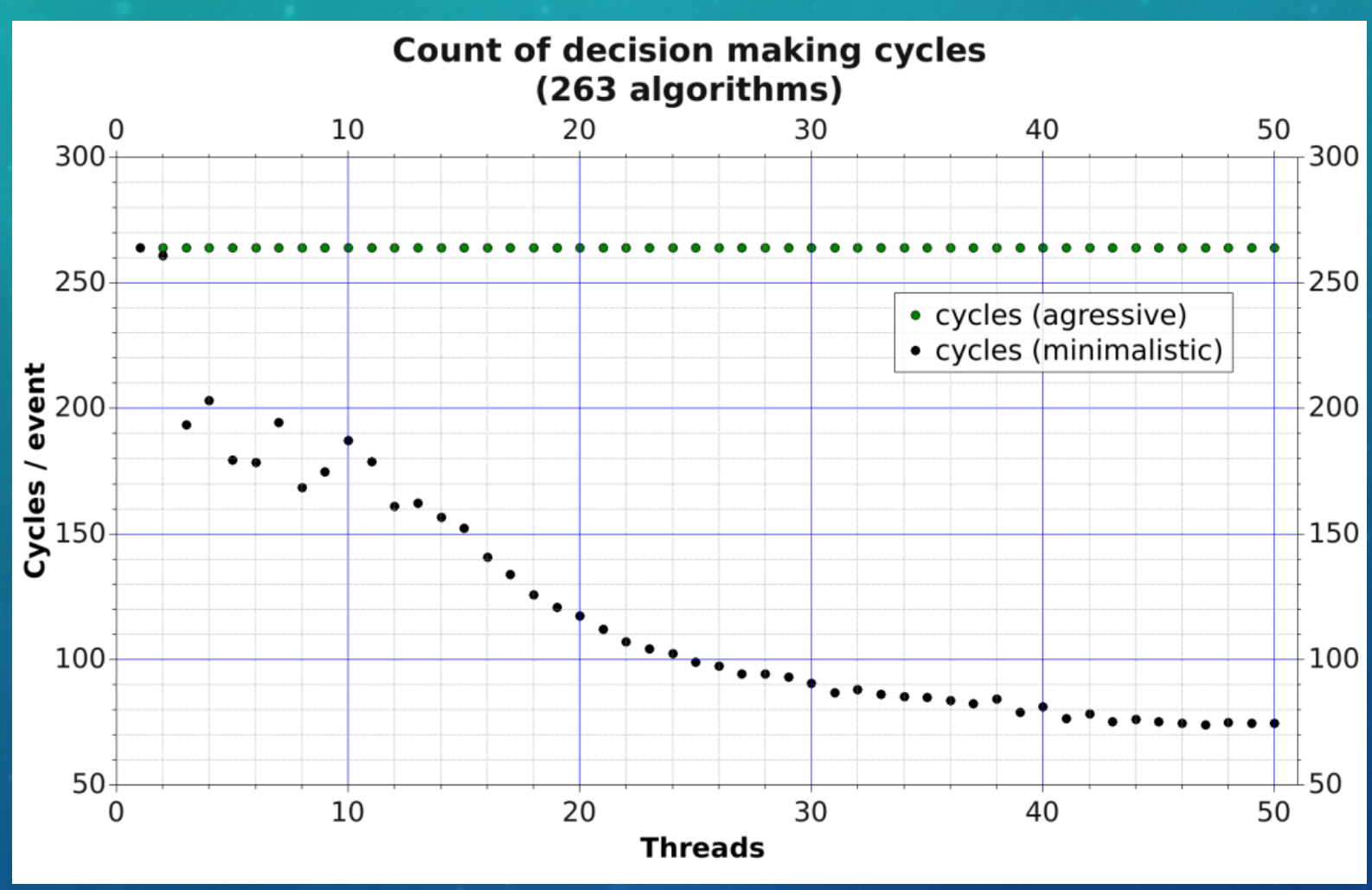

